\title{
Spatiotemporal Patterns of Activity in an Intact Mammalian Network with Single-Cell Resolution: Optical Studies of Nicotinic Activity in an Enteric Plexus
}

\author{
Ana Lía Obaid, ${ }^{1,2}$ Takeshi Koyano, ${ }^{1}$ Jon Lindstrom, ${ }^{1}$ Tetsuro Sakai, ${ }^{1}$ and B. M. Salzberg ${ }^{1,2}$ \\ Departments of ${ }^{1}$ Neuroscience and ${ }^{2}$ Physiology, University of Pennsylvania School of Medicine, Philadelphia, \\ Pennsylvania 19104-6074
}

Multiple Site Optical Recording of Transmembrane Voltage (MSORTV) has been used to measure, continuously and simultaneously, the spontaneous electrical activity from all of the neurons in individual ganglia or up to five interconnected ganglia of the submucous plexus of the guinea pig small intestine. These are the first optical recordings of electrical activity with single-cell resolution from a mammalian nervous system. They are used to investigate the effects of acute and chronic application of nicotine on the firing patterns of this neural network containing important cholinergic components. After washout of acutely applied nicotine, the firing rates of selected neurons were dramatically elevated. These results suggest that $n A C h R s$

Understanding behavior at the cellular level demands detailed knowledge of the network of neurons that mediate it. In the mammalian CNS, the three-dimensional structure of the brain, the dispersal of different neuronal subtypes into widely separated nuclei, and the often remote location of the relevant effector organs, make it virtually impossible to isolate the whole neural circuit for an entire behavior. However, one part of the mammalian nervous system, capable of mediating complex behaviors, can be isolated; this is the enteric nervous system (ENS) (Furness and Costa, 1987; Furness et al., 1994; Wood, 1994). Enteric neurons are clustered in ganglia that interconnect to form distinct plexuses in the gut wall. The myenteric plexus can be found between the longitudinal and circular muscle layers, and the submucous plexus between the circular muscle layer and the mucosa. The behavior of the effector systems in the gut (transporting epithelium, neuroendocrine cells, immune elements, blood vessels, and smooth muscle) is controlled by both of these networks acting in concert. Therefore, a detailed knowledge of synaptic interactions within and between ganglia, and of communication between the plexuses, is essential for a complete understanding of normal gastrointestinal function (Furness and Costa, 1987; Furness et al., 1994).

Cholinergic transmission within the ENS has been established by functional and electrophysiological studies (Kosterlitz and

\footnotetext{
Received Nov. 18, 1998; revised Feb. 1, 1999; accepted Feb. 2, 1999.

This work was supported by United States Public Health Service Grants NS35561 (A.L.O.), NS16824 (B.M.S.), NS11323 (J.L.), and CSTR (J.L.). We are grateful to Drs. Gregg B. Wells, Mark Nelson, Cameron Koch, and Martin Pring for fruitful discussions, to Michael J. Biercuk for his help with data analysis, and to Dr. Leslie Loew for his generous gift of di-8-ANEPPS.

Correspondence should be addressed to Dr. A. L. Obaid, Department of Neuroscience University of Pennsylvania School of Medicine, 234 Stemmler Hall Philadelphia, PA 19104-6074.

Copyright (C) 1999 Society for Neuroscience $\quad 0270-6474 / 99 / 193073-21 \$ 05.00 / 0$
}

that reversibly desensitize after exposure to nicotine may be responsible for the enhancement of activity that is observed after a brief application of this agonist. In addition, immunostaining with monoclonal antibodies was used to localize $\alpha 3$ / $\alpha 5, \alpha 7$, and $\beta 2 \mathrm{nAChR}$ subunits, and the results demonstrate the prevalence of $\alpha 3 / \alpha 5$. It is this $\alpha 3$-containing nAChR subtype that probably accounts for most of the excess activity elicited by nicotine application.

Key words: optical recording; enteric nervous system; submucous plexus; nicotinic ACh receptors; voltage-sensitive dye; di-8-ANEPPS; phototoxicity

Lees, 1964; Cooke, 1984; Furness and Costa, 1987; Johnson et al., 1996; Kadowaki et al., 1996) and by immunocytochemical characterization of the distribution of choline acetyltransferase (Schemann et al., 1993; Porter et al., 1996). Because $\sim 50 \%$ of the enteric neurons are cholinergic, and a considerable fraction of the fast excitatory transmission is sensitive to hexamethonium, a nicotinic antagonist, it was expected that acetylcholine receptors (AChRs) in the gut must include members of the family of nicotinic AChRs (nAChRs) that have been studied extensively in the CNS, peripheral ganglia, and neuromuscular junctions (Lindstrom, 1997). Indeed, Kirchgessner and Liu (1998) have reported immunoreactivity for $\mathrm{mAb35}$, a monoclonal antibody that recognizes $\alpha 1, \alpha 3$, and $\alpha 5$ subunits of nAChRs (Tzartos et al., 1981; Wang et al., 1996).

In addition, a complex relationship between smoking and inflammatory bowel disease has been demonstrated epidemiologically (Osborne and Stansby, 1994). Smokers are known to have a lower risk of ulcerative colitis, patients with ulcerative colitis who restart smoking tend to improve their symptoms, and nicotine enemas are therapeutic (Green et al., 1997a,b). In contrast, people who smoke have a higher risk of Crohn's disease, and patients with Crohn's disease who smoke have more symptoms, hospitalizations, and surgeries than do nonsmoking patients with this condition. An obvious candidate for the causative agent in the effects of tobacco on these diseases is nicotine, and its molecular targets must be presumed to be the family of neuronal nAChRs in the enteric nervous system (Kirchgessner and Liu, 1998).

We report here the use of Multiple Site Optical Recording of Transmembrane Voltage (MSORTV) (Salzberg et al., 1977; Salzberg, 1983; Grinvald et al., 1988; Rohr and Salzberg, 1994) to measure, continuously and simultaneously, the spontaneous and nicotine-induced activity from all of the individual neurons in rings of up to five interconnected ganglia of the submucous plexus 


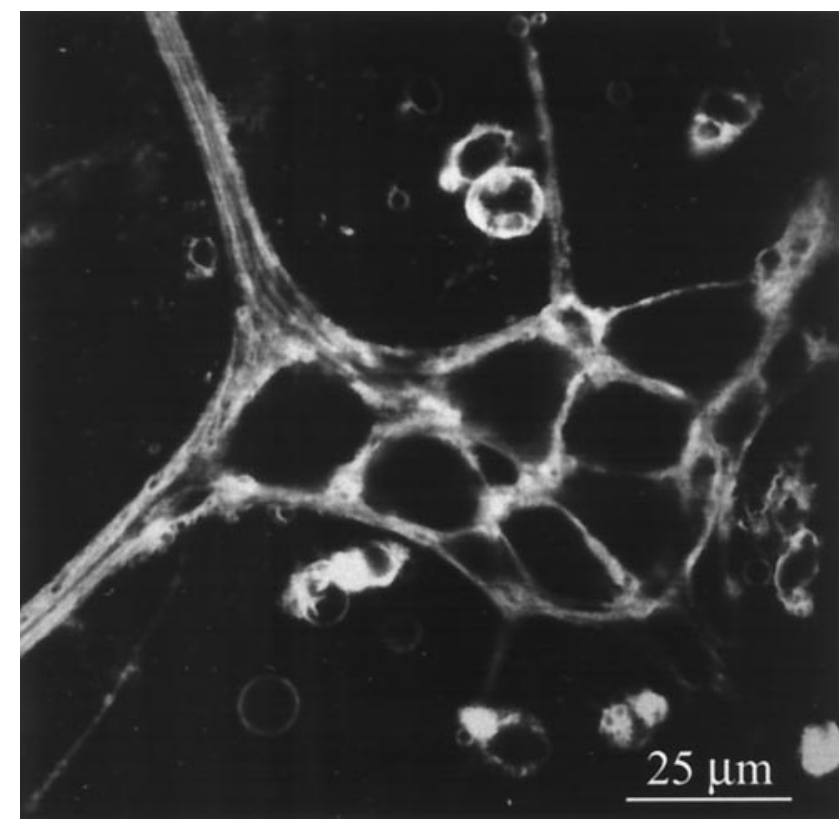

Figure 1. Confocal image of a typical ganglion from the submucous plexus of the guinea pig. The ganglion was photographed through a $100 \times$ planapochromat (1.4 NA) objective in a laser-scanning microscope (Carl Zeiss) after staining with the potentiometric probe di-8-ANEPPS. The section thickness was $0.5 \mu \mathrm{m}$. Here, brightness is directly proportional to fluorescence intensity, with no pseudo-gray scale used.

of the guinea pig small intestine. These are the first optical recordings of electrical activity with single-cell resolution from a mammalian nervous system. Our recordings demonstrate that exposure to nicotine can dramatically alter the patterns of electrical activity in submucosal networks and provide the basis for future investigation of the role or roles of nAChRs in the enteric nervous system.

Preliminary reports of this work have appeared in abstract form (Obaid et al., 1992, 1994, 1996b; Obaid and Salzberg, 1997).

\section{MATERIALS AND METHODS}

Tissue preparation. The isolated submucous plexuses were obtained from the small intestine of 150-200 gm Hartley guinea pigs (Charles River Laboratories, Wilmington, MA) that had been anesthetized by halothane inhalation and decapitated. These procedures were in accordance with institutional guidelines. The methods of dissection were essentially those of Hirst and McKirdy (1975). With the goal of reducing background fluorescence from dye-bound to residual smooth muscle and connective tissue, the isolated plexus was incubated for $2 \mathrm{hr}$ at room temperature in a Ringer's solution containing $50 \mathrm{U} / \mathrm{ml}$ collagenase VII (Sigma, St. Louis, MO) and $0.5 \mathrm{mg} / \mathrm{ml}$ protease IX (Sigma). After this treatment, the preparation was washed with and maintained in Medium 199 (Life Technologies, Gaithersburg, MD) containing 10\% fetal horse serum (Sigma) and antibiotics (penicillin, $100 \mathrm{U} / \mathrm{ml}$; streptomycin, 100 $\mu \mathrm{g} / \mathrm{ml}$ ) (Life Technologies) for 12-24 hr, at room temperature. For all of the experiments reported here, the incubations and maintenance took place in a chamber saturated with $95 \% \mathrm{O}_{2}$ and $5 \% \mathrm{CO}_{2}$. The resulting preparation, $\sim 4 \times 7 \mathrm{~mm}$, consisted of a network of 80-100 ganglia, each containing an average of 8-12 neurons, embedded in a muscle-free gossamer of connective tissue $\sim 30-\mu$ m-thick, containing the submucous neurons with their interconnecting nerve fibers and the submucosal vasculature. This preparation is virtually free of mechanical artifacts, an important consideration for optical recording. In addition, the somata in the submucous ganglia of the guinea pig are arranged in a quasi-two- -dimensional array, so that the individual neurons and the ganglia they constitute lie in a single optical section (Fig. 1) with no occlusion of their separate images.

Optical apparatus. The MSORTV system is based on a 464 element silicon photodiode array located in the image plane of an inverted microscope (Zeiss IM35; Carl Zeiss, Oberkochen, Germany) equipped for epifluorescence, which moves independently of a stage that is rigidly fixed to the $500 \mathrm{~kg}$ top of a vibration isolation table (Newport Research, Irvine, CA) (Parsons et al., 1991; Rohr and Salzberg, 1994). The entire measuring system is mounted on a large motorized, digitally encoded, and computer controlled X-Y positioner (Motion Master 2000 controller; Newport, Irvine, CA). Epi-illumination is provided by a $150 \mathrm{~W}$ xenon short arc lamp powered by an ultra-low-ripple, feedback-stabilized power supply (Opti-Quip, Highland Mills, NY). The incident light is made quasi-monochromatic using a heat filter (KG-1; Schott, Duryea, PA) and a high-Q interference filter $(530 \pm 25 \mathrm{~nm})$, and its intensity is adjusted using neutral density filters. Transillumination, for bright-field or phasecontrast viewing of the preparation, is provided by a $12 \mathrm{~V}, 100 \mathrm{~W}$ tungsten-halogen lamp powered by an ATE $75-15$ power supply (Kepco, Flushing, NY). The experimental preparation is held flat against a number 0 coverslip in a recording chamber attached to the fixed stage. A real image of the preparation is projected onto the 464 element array of silicon photodiodes (Centronics, Newbury Park, CA) that is positioned on a trinocular tube in the image plane of the objective. Photocurrents generated in each pixel of the array are converted to voltages, amplified in two stages, and then processed in two parallel acquisition systems (Fig. $2)$. In the first, the 464 high-level voltage signals are multiplexed and digitized using a pair of $5 \mu \mathrm{sec}, 16$-bit analog-to-digital (A/D) converters (Department of Cellular and Molecular Physiology Electronics Shop, Yale University School of Medicine, New Haven, CT) operating synchronously, to achieve a $400 \mathrm{kHz}$ throughput to a Motorola 68030 computer and an effective frame rate of $\sim 900 \mathrm{~Hz}$. In addition, the second stage amplifiers are AC-coupled, resulting in a gray scale resolution of $\sim 22$ bits. In the second acquisition system, all 464 analog signals are available at pin connectors on an octagonal patchboard matrix whose geometry mimics that of the array itself. Thirty-two plug-in cables allow the selection of an arbitrary subset of 32 detectors for high-speed acquisition at $330 \mathrm{kHz}$ (Computer Boards, Mansfield, MA), permitting a frame rate of up to $10 \mathrm{kHz}$ for this 32-pixel frame. In the experiments reported here, the 32-channel data were acquired at a frame rate of 2 $\mathrm{kHz}$ and were later analyzed using appropriate software (Data-Pac II; Run Technologies, Laguna Hills, CA).

Spatial resolution. In the optical system used here, a $100 \times$ objective permits recording reliably the electrical activity of cells as small as $7.5 \mu \mathrm{m}$ in diameter, but the field of view is restricted to a single ganglion. To record from rings of interconnected ganglia, we used a $40 \times$ objective. In this way, single-cell resolution is retained, although every detector averages the electrical activity over a square region $\sim 18 \mu \mathrm{m}$ on a side in the object plane. In this apparatus, a specially designed beam splitter can be moved into and out of the light path. This device exploits the high reflectivity of the silicon photodiode array. When combined with a projection lens, it relays an image of the preparation that is reflected by the photodiode array onto a small CCD camera connected to a frame grabber. In this way, the registration of the individual photodetector elements with the neurons in the image plane can be defined and preserved.

Optical recording. For the optical experiments, the preparation was mounted as indicated above in the recording chamber attached to the fixed stage of the inverted microscope. The tissue was then stained for at least $10 \mathrm{~min}$ with $50 \mu \mathrm{g} / \mathrm{ml}$ of the styryl dye (1-(3-sulfonatopropyl)-4-[ $\beta[2-$ (di- $n$-octylamino)-6-naphthyl]vinyl]pyridinium betaine) (di-8-ANEPPS) (Bedlack et al., 1992) in a Ringer's solution containing 0.47\% DMSO and $0.16 \%$ Pluronic F-127 plus $2.5 \mathrm{U} / \mathrm{ml}$ glucose oxidase (Sigma) and 875 $\mathrm{U} / \mathrm{ml}$ catalase (Sigma). In some of the experiments, the staining solution also contained $10 \mu \mathrm{M}$ astaxanthin (González and Tsien, 1997). The dye solution was kept in the chamber throughout the experiment, unless specified. All of the experiments were performed at room temperature $\left(22-25^{\circ} \mathrm{C}\right)$. Optical recordings of electrical activity with single-cell resolution were obtained from in vitro submucous plexus preparations using a $40 \times$ objective (DApo 40 UV, 1.3 NA, Olympus Optical, Tokyo, Japan). In an area $4 \times 7 \mathrm{~mm}, 80-100$ ganglia could be examined for spontaneous or evoked activity.

Phototoxicity. The phototoxicity associated with some of the most sensitive potentiometric dyes results from the production of reactive 


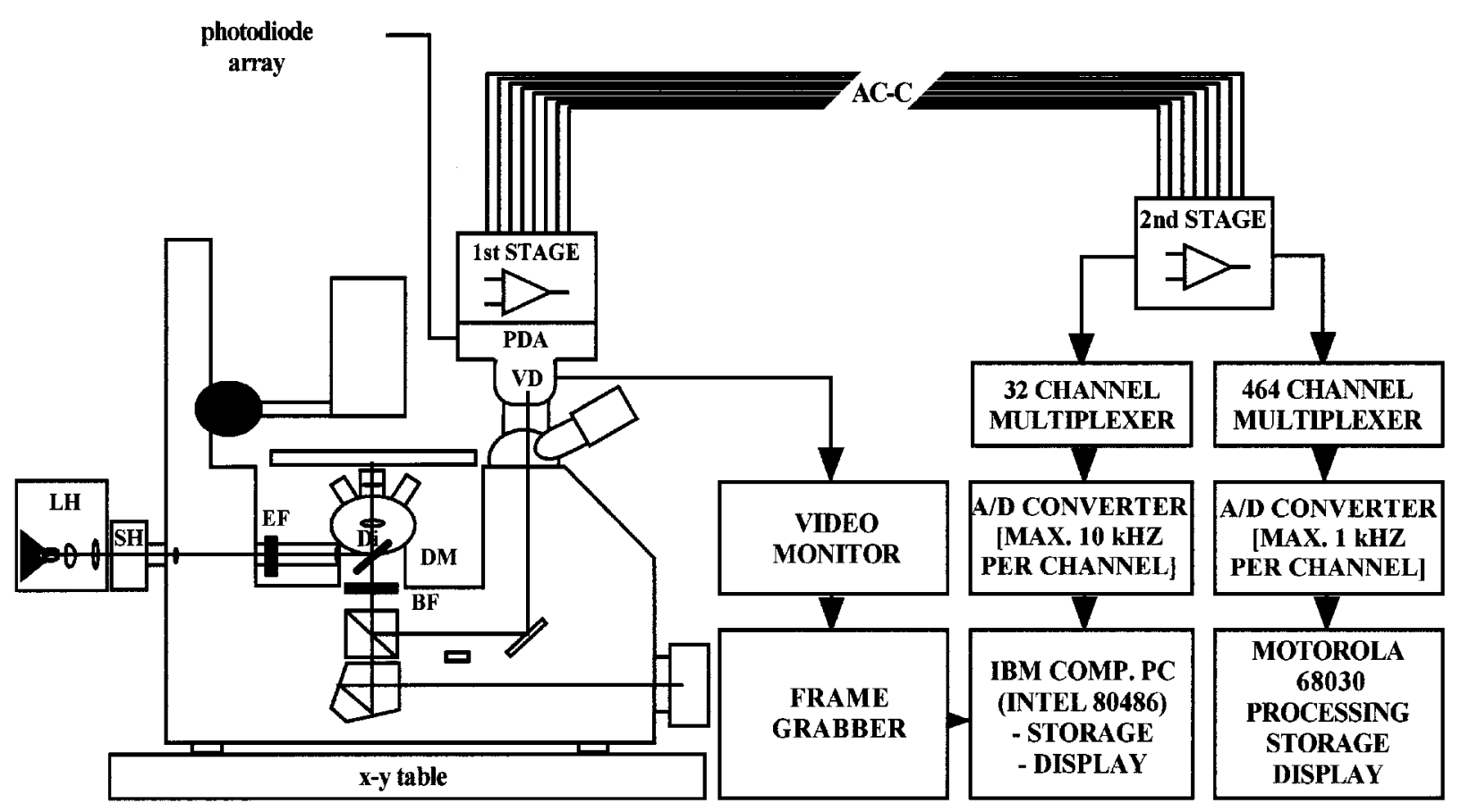

Figure 2. Schematic diagram of the system for MSORTV. On the left is an inverted microscope (IM-35; Carl Zeiss), mounted on a motorized digitally encoded and computer-controlled (Motion Master 2000 controller, Newport Research) X-Y positioner that moves independently of a fixed stage that is rigidly attached to a large (500 kg) vibration isolation table. A 464-element array of silicon photodiodes (Centronics, Newbury Park, CA) is positioned on the trinocular tube in the image plane of the objective. A specially designed beamsplitter couples the photodiode array to a CCD camera, through a projection lens, so that an image of the preparation can be superimposed on an image of the array itself, captured by a frame grabber, and viewed on a video monitor. Photocurrents generated by each pixel of the photodiode array are converted to voltages, amplified in two stages (with AC coupling between them), and then processed by the two parallel acquisition systems shown on the right. In the first (464 channel multiplexer), the 464 high-level voltage signals are multiplexed and digitized using a pair of $5 \mu \mathrm{sec}, 16$-bit $\mathrm{A} / \mathrm{D}$ converters operating synchronously to achieve a $400 \mathrm{kHz}$ throughput to a Motorola 68030 computer. In the second acquisition system (32 channel multiplexer), all 464 high-level analog signals are available at pin connectors on an octagonal patchboard matrix having the same geometry as the photodiode array. Thirty-two plug-in cables allow the selection of an arbitrary subset of 32 detectors for high-speed acquisition at $330 \mathrm{kHz}$, permitting a frame rate of up to $10 \mathrm{kHz}$ for this 32-pixel frame. LH, Lamp house; SH, shutter; $\mathrm{EF}$, emission filter; Di, direct illumination; DM, dichroic mirror; BF, barrier filter; PDA, photodiode array; VD, video camera.

singlet oxygen by the excited state of the dye molecule (Pooler, 1972; Oxford et al., 1977; Kalyanaraman et al., 1987). We found that we could lower the steady-state oxygen tension in an open bath, to levels that preserve normal physiology but significantly reduce photodynamic damage, by incorporating a mixture of glucose oxidase and catalase in the glucose containing Ringer's solution. In addition, we found that the animal carotenoid pigment astaxanthin (Di Mascio et al., 1990; González and Tsien, 1997) was helpful in reducing phototoxicity further when used in conjunction with glucose oxidase and catalase but was ineffective when used alone. The combination of these measures has permitted us to record continuously for up to $5 \mathrm{~min}$ with single-cell resolution from this intact mammalian neural network.

Processing of optical data. Despite the organization of guinea pig submucous ganglia as quasi-two-dimensional ensembles, the restricted spatial resolution of the 464-element photodiode array determines that the signals from one cell may be present on more than one photodiode channel, and that one channel may detect the signals from more than one cell (Salzberg et al., 1977). Sorting the raw data recorded by multiple photodiodes, therefore, requires user-driven procedures developed to identify and isolate the spike trains of the individual cells. The procedures used in this work used software modules from Data-Pac II (Run Technologies). Figure 3 illustrates this process.

Figure $3 A$ shows the image of a ganglion stained with di-8-ANEPPS, captured by a video frame grabber, with the image (enhanced) of the central region of the 464-element photodiode array superimposed. Because this experiment used a $40 \times$ objective (DApo $40 \mathrm{UV}, 1.3 \mathrm{NA}$, Olympus), each photodetector monitored a square region of the preparation $\sim 18 \mu \mathrm{m}$ on a side. The numbers identify 30 of the 32 selected photodetectors positioned over the area of interest, whose outputs were recorded at a $2 \mathrm{kHz}$ frame rate by the PC-based acquisition system. In this and subsequent images, the gray scale has been inverted for clarity so that increasing fluorescence intensity from membranes stained with di-8-ANEPPS is represented by darker gray levels. Figure $3 B$ shows the electrical activity, represented as fluorescence changes $(\Delta \mathrm{F}$, in arbitrary units), over a $1 \mathrm{sec}$ period, recorded by photodiodes numbered 12 and 13 . Figure $3 B$, top , shows the raw optical data $(\Delta \mathrm{F})$. Figure $3 B$, bottom, shows the same records after digital filtering using a $20 \mathrm{~Hz}$ high-pass filter, followed by three $1 \mathrm{msec}$ smoothing windows. Figure $3 \mathrm{C}$ shows the filtered outputs of the 16 channels that monitored the ganglion over a 5 sec period. Spike assignment to individual neurons in the image of the submucous ganglion (spike sorting) was accomplished by examining the distribution of all action potentials across the 32 photodiode channels and using the spatial relationship between the photodiode array elements and the images of the cells together with coincidence information. The actual extraction of spike times was done with a simple voltage threshold followed by location of the zero-crossing of the differentiated optical data. Thus, the final spike times that were assigned to the cells were the peak times of the action potentials. This process was largely automated, but the operator retained sufficient control to exclude spurious events. Spike-sorting analysis of the neuronal activity shown in Figure $3 C$ revealed that the activity recorded by these 16 active channels was confined to eight active neurons, labeled from $A$ to $H$, whose spike trains are shown in Figure $3 D$. Figure $3 E$ identifies those neurons within the ganglion. Tables containing the peak times of the spike trains for each active neuron within the field of view were stored as files. Therefore, in addition to their use in generating the raster diagrams that allow direct, visual comparison of the firing patterns of the neurons (Fig. 3D), they also were used as input to software that creates an animated image of the ganglia, flashing each neuron in time with its individual action potentials. The animation files associated with selected figures can be accessed at the authors' website (http://loco1.med.upenn.edu/ animation).

The experiment in Figure 3 demonstrates several important points: (1) 
$\mathbf{A}$

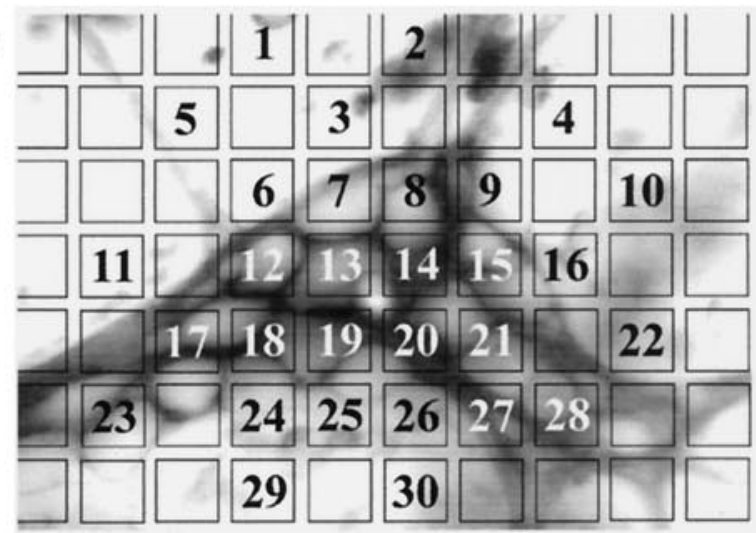

B

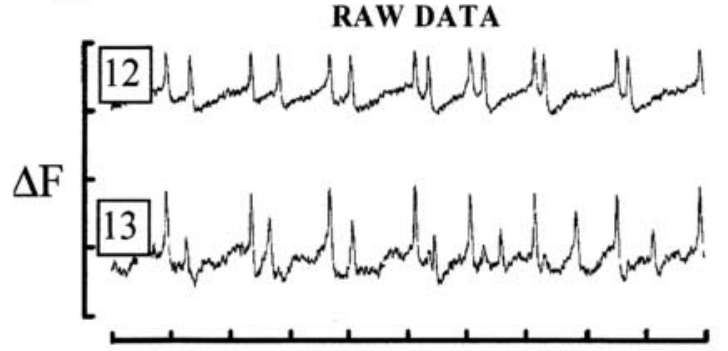

DIGITALLY FILTERED DATA

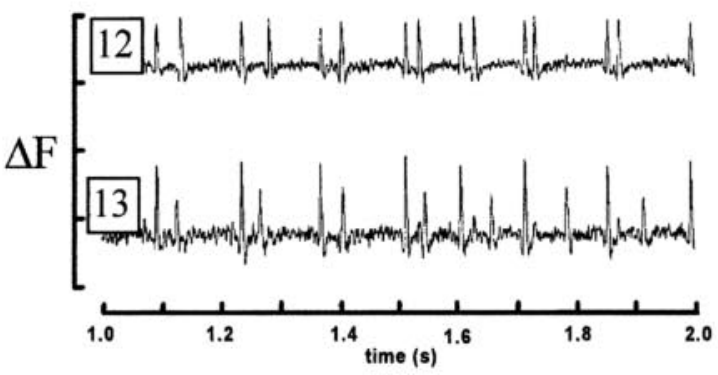

Figure 3. The processing of raw optical data. $A$, Image of a submucous plexus ganglion stained with di-8-ANEPPS, with the image of the central region of the photodiode array superimposed. A $40 \times$ objective (DApo $40 \mathrm{UV}, 1.3 \mathrm{NA}$, Olympus) results in each detector monitoring a square region of the ganglion 18 $\mu \mathrm{m}$ on a side. The numbers identify 30 of the 32 selected detectors whose outputs were recorded by the 32 channel recording system. Here, the gray scale has been inverted for clarity, so that increasing fluorescence intensity is represented by darker shades of gray. $B$, Digital outputs of photodetectors numbered 12 and 13, over a $1 \mathrm{sec}$ period. Top, Raw data. Bottom, Digitally filtered data. AC coupling time constant, $110 \mathrm{msec}$. $C$, Digitally filtered outputs of the 16 photodetectors positioned over the image of the ganglion, over a $5 \mathrm{sec}$ period. $D$, Raster plot that summarizes the spike trains of the eight individual active neurons that were identified by spike-sorting analysis of the data shown in $C$. $E$, Visual identification of the eight neurons whose spike activity is depicted in $D$.
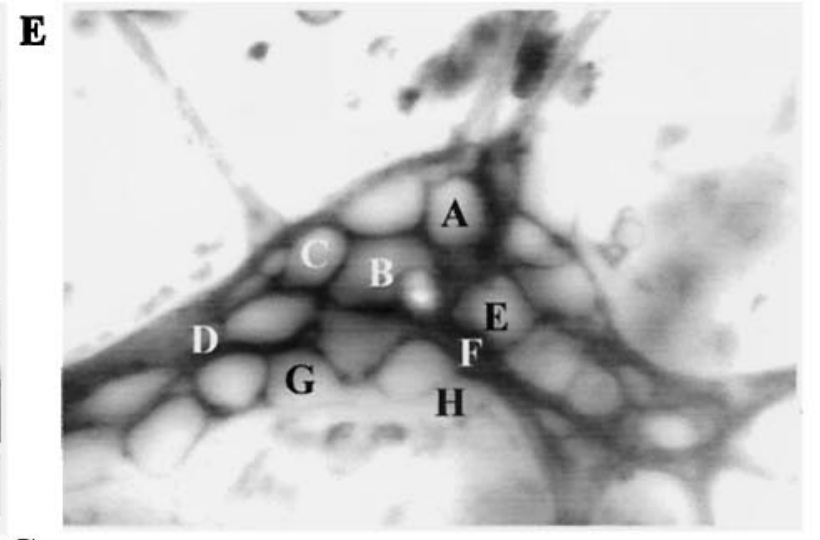

C
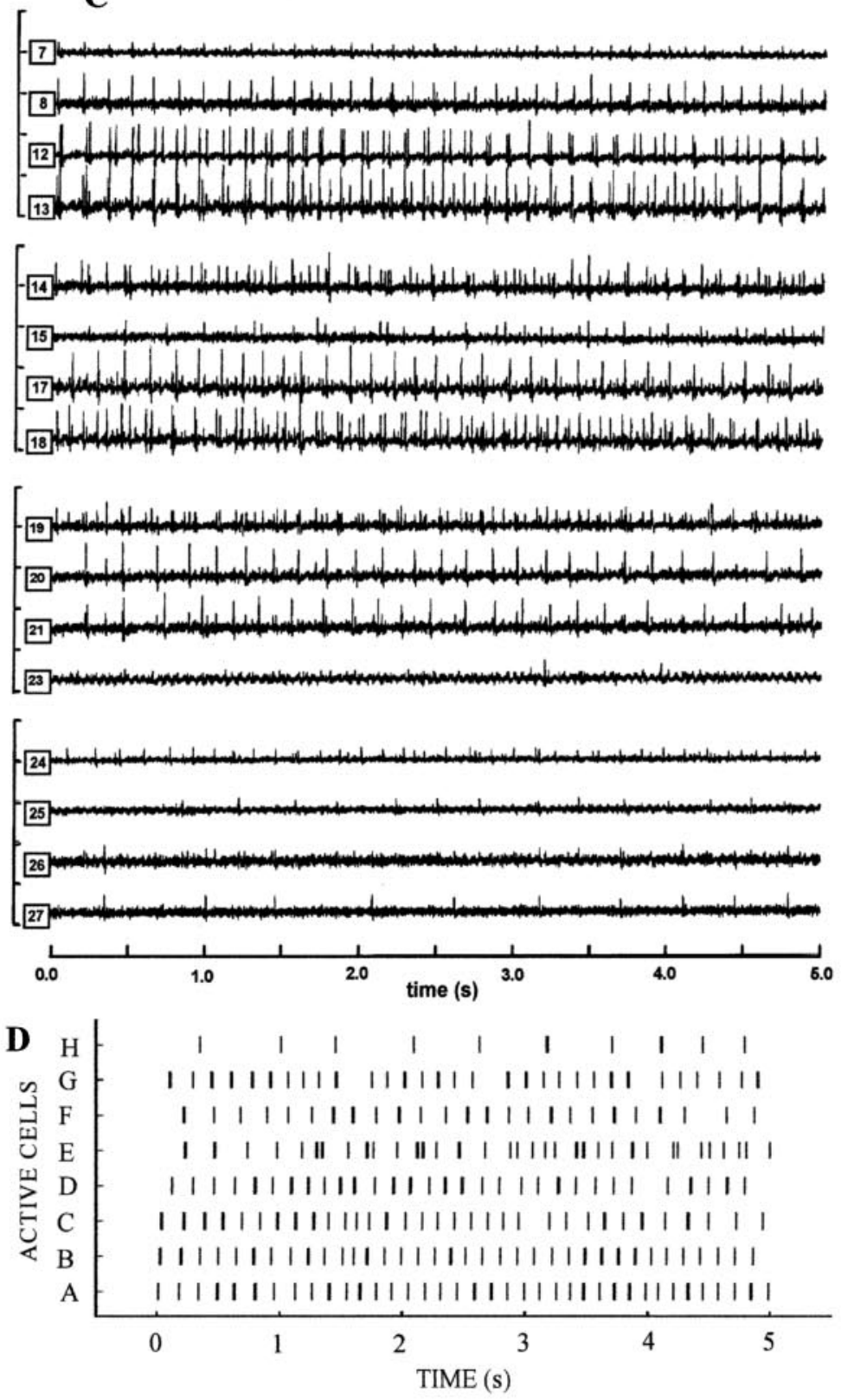


\begin{tabular}{|c|c|c|c|c|c|}
\hline Antibody & $\begin{array}{l}\text { nAChR subunit } \\
\text { recognized }\end{array}$ & Immunogen & $\begin{array}{l}\text { Species } \\
\text { immunized }\end{array}$ & Dilution & $\begin{array}{l}\text { Original description and/or early use } \\
\text { in enteric neurons }\end{array}$ \\
\hline mAb35 & $\alpha 1, \alpha 3, \alpha 5$ & Electric organ $\mathrm{nAChR}$ & Rat & $1: 5000$ & $\begin{array}{l}\text { Tzartos et al., 1981; (Kirchgessner } \\
\text { and Liu, 1998) }\end{array}$ \\
\hline $\mathrm{mAb} 210$ & $\alpha 1, \alpha 3, \alpha 5$ & Mammalian muscle nAChR & Rat & $1: 5000$ & Tzartos et al., 1987 \\
\hline mAb295 & $\beta 2$ & Rat $\alpha 4 \beta 2 \mathrm{nAChR}$ & Rat & $1: 400$ & Whiting and Lindstrom, 1988 \\
\hline mAb306 & $\alpha 7$ & Rat and chicken $\alpha 7 \mathrm{nAChR}$ & Mouse & $1: 2000$ & Schoepfer et al., 1990 \\
\hline$\alpha \mathrm{NPY}$ antiserum & - & - & Rabbit & $1: 5000$ & (Furness et al., 1984) \\
\hline$\alpha \mathrm{VIP}$ antiserum & - & - & Rabbit & $1: 5000$ & (Furness and Costa, 1979) \\
\hline
\end{tabular}

at $40 \times$ magnification, single-cell resolution was preserved; (2) simple spike-sorting protocols accomplished the reduction of complex patterns of activity (Fig. 3C) into simple spike trains associated with individual neurons (Fig. 3D); and (3) the patterns of spontaneous activity that emerge were associated with a relatively small number of neurons within each ganglion.

Immunocytochemical identification of $n A C h R$ subunits. Immunofluorescence experiments were performed on whole mounts of fixed submucous plexus. The preparations, obtained as indicated above, were washed with PBS to eliminate any residual fetal horse serum and fixed in $10 \%$ buffered formalin (Fisher Scientific, Houston, TX) for $24 \mathrm{hr}$ at $4^{\circ} \mathrm{C}$. Nonspecific binding was reduced by using $4 \%(\mathrm{v} / \mathrm{v})$ normal goat serum (Jackson ImmunoResearch, West Grove, PA), with or without Triton $\mathrm{X}-100(0.5 \%)$, in PBS containing $10 \mathrm{mM} \mathrm{NaN}_{3}\left(\mathrm{PBS}-\mathrm{NaN}_{3}\right)$, for $2 \mathrm{hr}$ at room temperature. The preparations were then exposed for $24-48 \mathrm{hr}$ to monoclonal antibodies (mAbs) raised against specific $\mathrm{nAChR}$ subunits (Table 1), all of which have previously been described (Tzartos et al., 1981, 1987; Whiting and Lindstrom, 1988; Schoepfer et al., 1990; Lindstrom, 1996). These antibodies were diluted in $\mathrm{PBS}-\mathrm{NaN}_{3}$ containing $4 \%$ normal goat serum, to a final concentration of 5-30 nM. For doublelabeling experiments, antibodies raised in rabbit against porcine neuropeptide $\mathrm{Y}(\alpha \mathrm{NPY})$ and porcine vasoactive intestinal peptide $(\alpha \mathrm{VIP})$ (Incstar Corporation, Stillwater, MN), were used in conjunction with $\mathrm{nAChR}$ antibodies (raised against rat or mouse). Affinity-purified, goat anti-rat, goat anti-mouse, and goat anti-rabbit secondary antibodies conjugated with indocarbocyanine, fluorescein, or Texas Red, were obtained from Jackson ImmunoResearch and used at 1:1000 dilution in PBS$\mathrm{NaN}_{3}$ containing $4 \%$ normal goat serum. For double staining, two secondary antibodies, tagged with different labels, were applied simultaneously. Staining with these secondary antibodies (24-48 hr) was performed at $4^{\circ} \mathrm{C}$. Rinsing steps lasted $30 \mathrm{~min}$ (three times for $10 \mathrm{~min}$ each) in $\mathrm{PBS}-\mathrm{NaN}_{3}$, at room temperature. The tissue was mounted in Pro-Long (Molecular Probes, Eugene, OR) and kept at $4^{\circ} \mathrm{C}$ until examined. Every experiment included parallel controls, in which whole mounts were incubated with $\mathrm{PBS}-\mathrm{NaN}_{3}$ containing $4 \%$ normal goat serum in the absence of primary antibodies and subsequently stained with the secondary antibodies.

Immunofluorescence was visualized using a Leica TCS-NT laserscanning confocal microscope, equipped with either a $40 \times$ (Leica, 1.25 NA, oil PL APO) or a $100 \times$ (Leica UV, 1.4 NA oil, PL APO) objective. Usually, 12-32 optical sections were taken at $0.5-1.0 \mu \mathrm{m}$ intervals. Images acquired at $1024 \times 1024$ pixel resolution were processed using Adobe Photoshop 5.0 (Adobe Systems, Mountain View, CA).

\section{RESULTS}

\section{Optical recording from rings of interconnected ganglia with maintenance of single-cell resolution}

Recording from multiple interconnected ganglia is preferable to recording from single ganglia, despite the circumstance that each of these ganglia typically contains sensory, intermediate, and motor neurons. Although numerous electrophysiological studies using the submucous plexus have included intracellular recordings from pairs of neurons within single ganglia, the effort to identify synaptically coupled pairs has been frustrating. A possible explanation is that the functional units of the submucous plexus are supraganglionic networks that share neuronal pools, rather than anatomically defined ganglia. Simultaneous optical recording of electrical activity from rings of interconnected ganglia with single-cell resolution, combined with appropriate analytical tools (Gerstein and Aertsen, 1985; Gerstein et al., 1985; Maldonado and Gerstein, 1996), should permit us to examine whether sets of functionally connected neurons are found primarily within single ganglia or are distributed among several ganglia.

Figure 4 illustrates the analysis of electrical activity in a ring of interconnected ganglia monitored optically. Figure $4 A$ shows the image of the ring of ganglia, after staining with di-8-ANEPPS, with the image of the photodiode array superimposed. Figure $4 B$ illustrates the visual identification of individual neurons within the ring, whose firing patterns are depicted in Figure $4 C$. This panel shows the raster plot that summarizes the firing patterns of the eight active neurons identified by spike sorting in this $180 \mathrm{sec}$ recording. In this experiment, phototoxicity was minimized by using glucose oxidase and catalase in the staining solution (see Materials and Methods).

In this record, complex patterns of multineuronal activity begin to emerge. Figure $4 C$, for example, hints at the presence of shared inputs that appear to modulate synchronously (at $t \sim 25 \mathrm{sec}$ and at $t \sim 90 \mathrm{sec}$ ) the firing rates of cells from different ganglia (neurons $B, C$, and $H$ at $t \sim 25 \mathrm{sec}$ ). This characteristic behavior strongly suggests the existence of a supraganglionic organization to the network (Obaid et al., 1996a,b).

Although the activity illustrated in Figure 4 is a typical example of spontaneous behavior in rings of submucosal ganglia, it is extremely difficult to compare quantitatively the spatiotemporal patterns of firing of one preparation with those of another. This is because, in addition to the variability from cell to cell and ganglion to ganglion, there is a temporal organization intrinsic to the bursts that defies easy description. As a first step toward capturing the average behavior of these networks, we have tabulated (Table 2, control) the average firing frequency of all of the active cells from 14 different recording sessions, from six different preparations that were treated identically. These were calculated by dividing the number of action potentials in each spike train by the duration of the recording. Pooling of the data, although simplistic, is justified by the apparent similarity in the firing behavior of active neurons from different ganglia and from different preparations. It should be noted that this procedure, by including the silent periods, severely underestimates the intraburst firing frequency of the active cells [more sophisticated analyses, such as the random walk models of Gerstein and Mandelbrot (1964) do not seem justified at present because the size of 

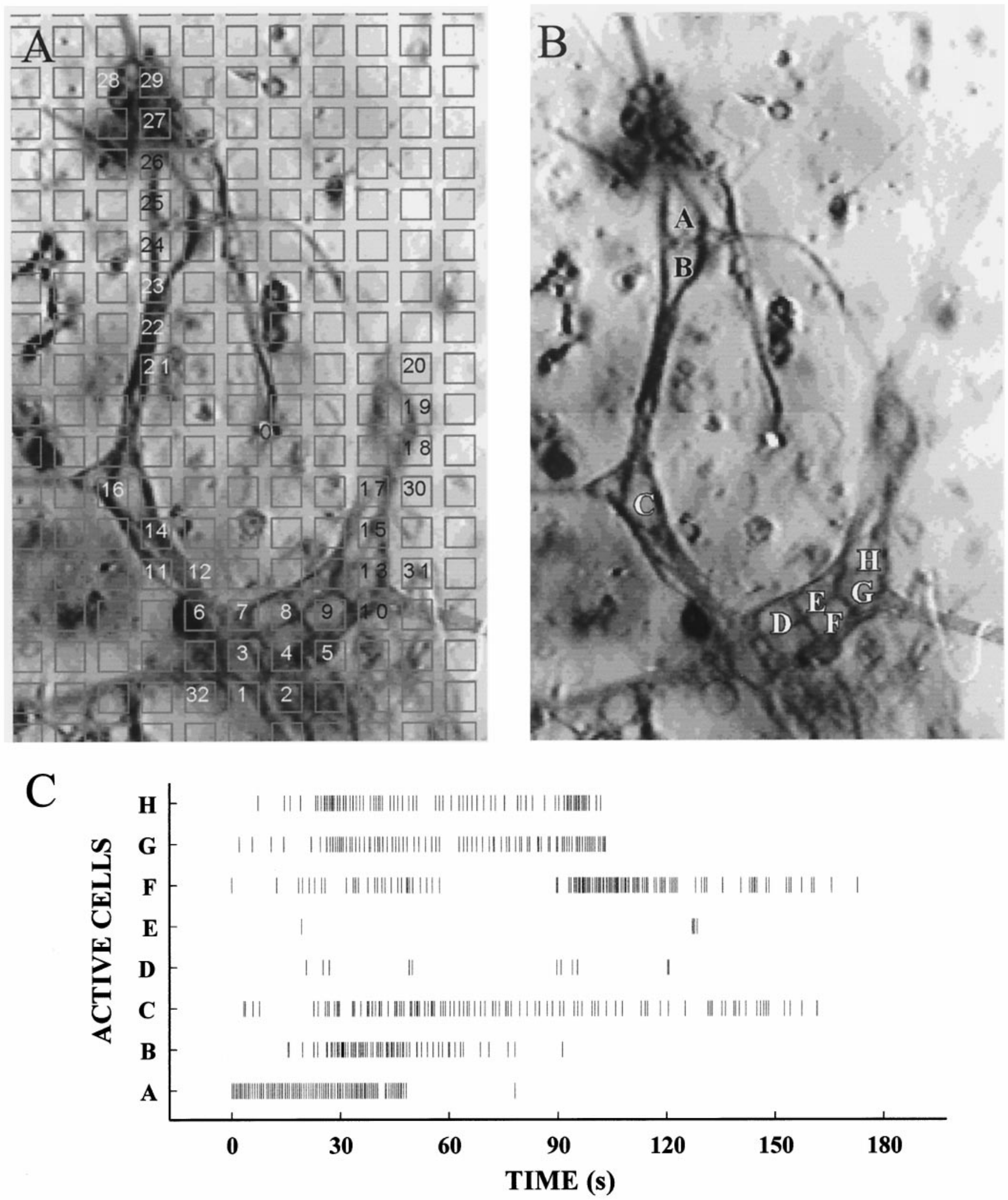

Figure 4. Optical recording of electrical activity from individual neurons in a ring of interconnected ganglia. $A$, The image of the ring of ganglia, after staining with di-8-ANEPPS, with the image of the central region of the photodiode array superimposed. A $40 \times$ objective (DApo 40 UV, 1.3 NA, Olympus) results in each detector monitoring a square region of the ganglion $18 \mu \mathrm{m}$ on a side. The gray scale has been inverted so that increasing fluorescence intensity is represented by darker shades of gray. $B$, Visual identification of individual neurons whose firing pattern is summarized in $C$. $C$, Raster plot depicting the spike activity of the eight neurons that were spontaneously active during the 3 min recording period (see Table 2 , control, preparation 1, 1R). The associated animation can be accessed at the authors' website (http://loco1.med.upenn.edu/ animation). 
Table 2. Effect of nicotine on the average firing frequency of submucosal neurons

\begin{tabular}{|c|c|c|c|c|c|}
\hline Preparation \# & Record \# & Cell & \# of spikes & Duration (sec) & Avg. frequency $(\mathrm{Hz})$ \\
\hline \multicolumn{6}{|l|}{ Control } \\
\hline \multirow[t]{8}{*}{1} & $1(\mathrm{R})$ & A & 89 & 180 & 0.49 \\
\hline & & $\mathrm{B}$ & 67 & 180 & 0.37 \\
\hline & & $\mathrm{C}$ & 103 & 180 & 0.57 \\
\hline & & $\mathrm{D}$ & 11 & 180 & 0.06 \\
\hline & & $\mathrm{E}$ & 5 & 180 & 0.03 \\
\hline & & $\mathrm{F}$ & 113 & 180 & 0.63 \\
\hline & & G & 83 & 180 & 0.46 \\
\hline & & $\mathrm{H}$ & 74 & 180 & 0.41 \\
\hline \multirow[t]{2}{*}{2} & $1(\mathrm{G})$ & $\mathrm{A}$ & 2 & 120 & 0.02 \\
\hline & & B & 60 & 120 & 0.50 \\
\hline \multirow[t]{5}{*}{3} & $1(\mathrm{G})$ & A & 119 & 180 & 0.66 \\
\hline & & B & 36 & 180 & 0.20 \\
\hline & & $\mathrm{C}$ & 27 & 180 & 0.15 \\
\hline & & $\mathrm{D}$ & 30 & 180 & 0.17 \\
\hline & & $\mathrm{E}$ & 13 & 180 & 0.07 \\
\hline \multirow[t]{2}{*}{4} & $1(\mathrm{G})$ & A & 9 & 60 & 0.15 \\
\hline & & B & 5 & 60 & 0.08 \\
\hline \multirow[t]{16}{*}{5} & $1(\mathrm{G})$ & A & 73 & 120 & 0.61 \\
\hline & $2(\mathrm{G})$ & A & 30 & 180 & 0.17 \\
\hline & & B & 45 & 180 & 0.25 \\
\hline & & $\mathrm{C}$ & 116 & 180 & 0.64 \\
\hline & & $\mathrm{D}$ & 25 & 180 & 0.14 \\
\hline & & $\mathrm{E}$ & 70 & 180 & 0.39 \\
\hline & $3(\mathrm{G})$ & A & 23 & 180 & 0.13 \\
\hline & & B & 112 & 180 & 0.62 \\
\hline & & $\mathrm{C}$ & 1 & 180 & 0.01 \\
\hline & & $\mathrm{D}$ & 10 & 180 & 0.06 \\
\hline & $4(\mathrm{G})$ & A & 163 & 140 & 1.16 \\
\hline & & B & 9 & 140 & 0.06 \\
\hline & $5(\mathrm{G})$ & A & 44 & 120 & 0.37 \\
\hline & & B & 1 & 120 & 0.01 \\
\hline & & $\mathrm{C}$ & 10 & 120 & 0.08 \\
\hline & $6(\mathrm{G})$ & A & 121 & 80 & 1.51 \\
\hline \multirow[t]{19}{*}{6} & $1(\mathrm{G})$ & A & 6 & 120 & 0.05 \\
\hline & & B & 5 & 120 & 0.04 \\
\hline & & $\mathrm{C}$ & 19 & 120 & 0.16 \\
\hline & & $\mathrm{D}$ & 20 & 120 & 0.17 \\
\hline & & $\mathrm{E}$ & 9 & 120 & 0.08 \\
\hline & $2(\mathrm{G})$ & A & 34 & 100 & 0.34 \\
\hline & & B & 123 & 100 & 1.23 \\
\hline & $3(\mathrm{G})$ & A & 18 & 90 & 0.20 \\
\hline & & B & 97 & 90 & 1.08 \\
\hline & & $\mathrm{C}$ & 3 & 90 & 0.03 \\
\hline & & $\mathrm{D}$ & 25 & 90 & 0.28 \\
\hline & & $\mathrm{E}$ & 35 & 90 & 0.39 \\
\hline & $4(\mathrm{G})$ & A & 28 & 140 & 0.20 \\
\hline & & B & 12 & 140 & 0.09 \\
\hline & & $\mathrm{C}$ & 72 & 140 & 0.51 \\
\hline & & $\mathrm{D}$ & 55 & 140 & 0.39 \\
\hline & & $\mathrm{E}$ & 25 & 140 & 0.18 \\
\hline & & $\mathrm{F}$ & 4 & 140 & 0.03 \\
\hline & & G & 6 & 140 & 0.04 \\
\hline \multicolumn{6}{|c|}{ Average firing frequency: $0.32 \mathrm{~Hz}$} \\
\hline \multicolumn{6}{|c|}{$\%$ of active cells with average firing frequency $\leq 0.5 \mathrm{~Hz}: 79 \%$} \\
\hline \multicolumn{6}{|c|}{$\%$ of active cells with average firing frequency between 0.5 and $1 \mathrm{H} .0 \mathrm{~Hz}: 13 \%$} \\
\hline \multicolumn{6}{|c|}{$\%$ of active cells with average firing frequency between 1.0 and $1.5 \mathrm{~Hz}: 6 \%$} \\
\hline \multicolumn{6}{|c|}{$\%$ of active cells with average firing frequency between 1.5 and $2.0 \mathrm{~Hz}: 2 \%$} \\
\hline$\%$ of active cel & average firi & eque & $\geq 2.0 \mathrm{~Hz}: 0 \%$ & & \\
\hline
\end{tabular}




\begin{tabular}{|c|c|c|c|c|c|}
\hline Preparation \# & Record \# & Cell & \# of spikes & Duration (sec) & Avg. frequency $(\mathrm{Hz})$ \\
\hline \multicolumn{6}{|l|}{ Acute nicotine } \\
\hline \multirow[t]{5}{*}{1} & $1(\mathrm{G})$ & A & 19 & 180 & 0.11 \\
\hline & & B & 30 & 180 & 0.17 \\
\hline & & $\mathrm{C}$ & 3 & 180 & 0.02 \\
\hline & & $\mathrm{D}$ & 4 & 180 & 0.02 \\
\hline & & $\mathrm{E}$ & 544 & 180 & 3.02 \\
\hline \multirow[t]{8}{*}{2} & $1(\mathrm{G})$ & A & 54 & 80 & 0.68 \\
\hline & & $\mathrm{B}$ & 90 & 80 & 1.13 \\
\hline & & $\mathrm{C}$ & 190 & 80 & 2.38 \\
\hline & & $\mathrm{D}$ & 6 & 80 & 0.08 \\
\hline & & $\mathrm{E}$ & 1 & 80 & 0.01 \\
\hline & & $\mathrm{F}$ & 1 & 80 & 0.01 \\
\hline & & $\mathrm{G}$ & 23 & 80 & 0.29 \\
\hline & & $\mathrm{H}$ & 12 & 80 & 0.15 \\
\hline \multirow[t]{13}{*}{3} & $1(\mathrm{G})$ & A & 2 & 40 & 0.05 \\
\hline & & $\mathrm{B}$ & 14 & 40 & 0.35 \\
\hline & & $\mathrm{C}$ & 116 & 40 & 2.90 \\
\hline & & $\mathrm{D}$ & 10 & 40 & 0.25 \\
\hline & & $\mathrm{E}$ & 30 & 40 & 0.75 \\
\hline & & $\mathrm{F}$ & 3 & 40 & 0.08 \\
\hline & & G & 41 & 40 & 1.03 \\
\hline & & $\mathrm{H}$ & 30 & 40 & 0.75 \\
\hline & & I & 21 & 40 & 0.53 \\
\hline & & $\mathrm{J}$ & 37 & 40 & 0.93 \\
\hline & $2(\mathrm{G})$ & A & 272 & 60 & 4.53 \\
\hline & & B & 217 & 60 & 3.62 \\
\hline & & $\mathrm{C}$ & 17 & 60 & 0.28 \\
\hline \multirow[t]{20}{*}{4} & $1(\mathrm{R})$ & A & 3 & 35 & 0.09 \\
\hline & & B & 75 & 35 & 2.14 \\
\hline & & $\mathrm{C}$ & 77 & 35 & 2.20 \\
\hline & & $\mathrm{D}$ & 57 & 35 & 1.63 \\
\hline & & $\mathrm{E}$ & 6 & 35 & 0.17 \\
\hline & & $\mathrm{F}$ & 58 & 35 & 1.66 \\
\hline & & G & 87 & 35 & 2.49 \\
\hline & & $\mathrm{H}$ & 58 & 35 & 1.66 \\
\hline & & I & 111 & 35 & 3.17 \\
\hline & & $\mathrm{J}$ & 50 & 35 & 1.43 \\
\hline & $2(\mathrm{G})$ & A & 6 & 45 & 0.13 \\
\hline & & B & 7 & 45 & 0.16 \\
\hline & & $\mathrm{C}$ & 8 & 45 & 0.18 \\
\hline & & $\mathrm{D}$ & 2 & 45 & 0.04 \\
\hline & & $\mathrm{E}$ & 75 & 45 & 1.67 \\
\hline & & $\mathrm{F}$ & 7 & 45 & 0.16 \\
\hline & & $\mathrm{G}$ & 76 & 45 & 1.69 \\
\hline & & $\mathrm{H}$ & 300 & 45 & 6.67 \\
\hline & & I & 130 & 45 & 2.89 \\
\hline & & $\mathrm{J}$ & 43 & 45 & 0.96 \\
\hline \\
\hline \multicolumn{6}{|c|}{$\%$ of active cells with average firing frequency $\leq 0.5 \mathrm{~Hz}: 44 \%$} \\
\hline \multicolumn{6}{|c|}{$\%$ of active cells with average firing frequency between 0.5 and $1 \mathrm{H} .0 \mathrm{~Hz}: 13 \%$} \\
\hline \multicolumn{6}{|c|}{$\%$ of active cells with average firing frequency between 1.0 and $1.5 \mathrm{~Hz}: 7 \%$} \\
\hline \multicolumn{6}{|c|}{$\%$ of active cells with average firing frequency between 1.5 and $2.0 \mathrm{~Hz}: 11 \%$} \\
\hline \multicolumn{6}{|c|}{$\%$ of active cells with average firing frequency $\geq 2.0 \mathrm{~Hz}: 25 \%$} \\
\hline \multicolumn{6}{|c|}{ Chronic nicotine } \\
\hline \multirow[t]{4}{*}{1} & $1(\mathrm{G})$ & A & 42 & 60 & 0.70 \\
\hline & & $\mathrm{B}$ & 6 & 60 & 0.10 \\
\hline & & $\mathrm{C}$ & 1 & 60 & 0.02 \\
\hline & & $\mathrm{D}$ & 2 & 60 & 0.03 \\
\hline
\end{tabular}




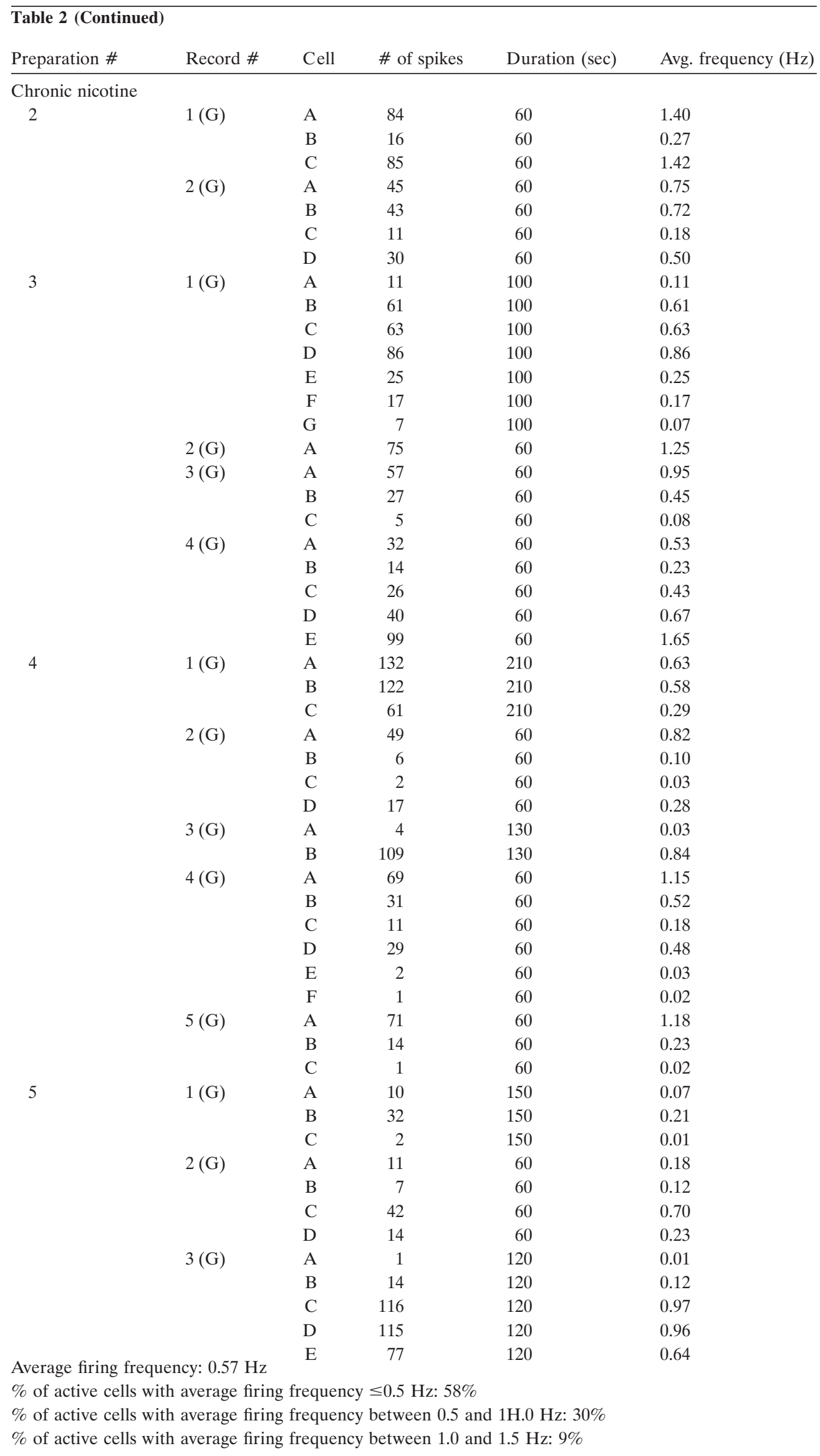




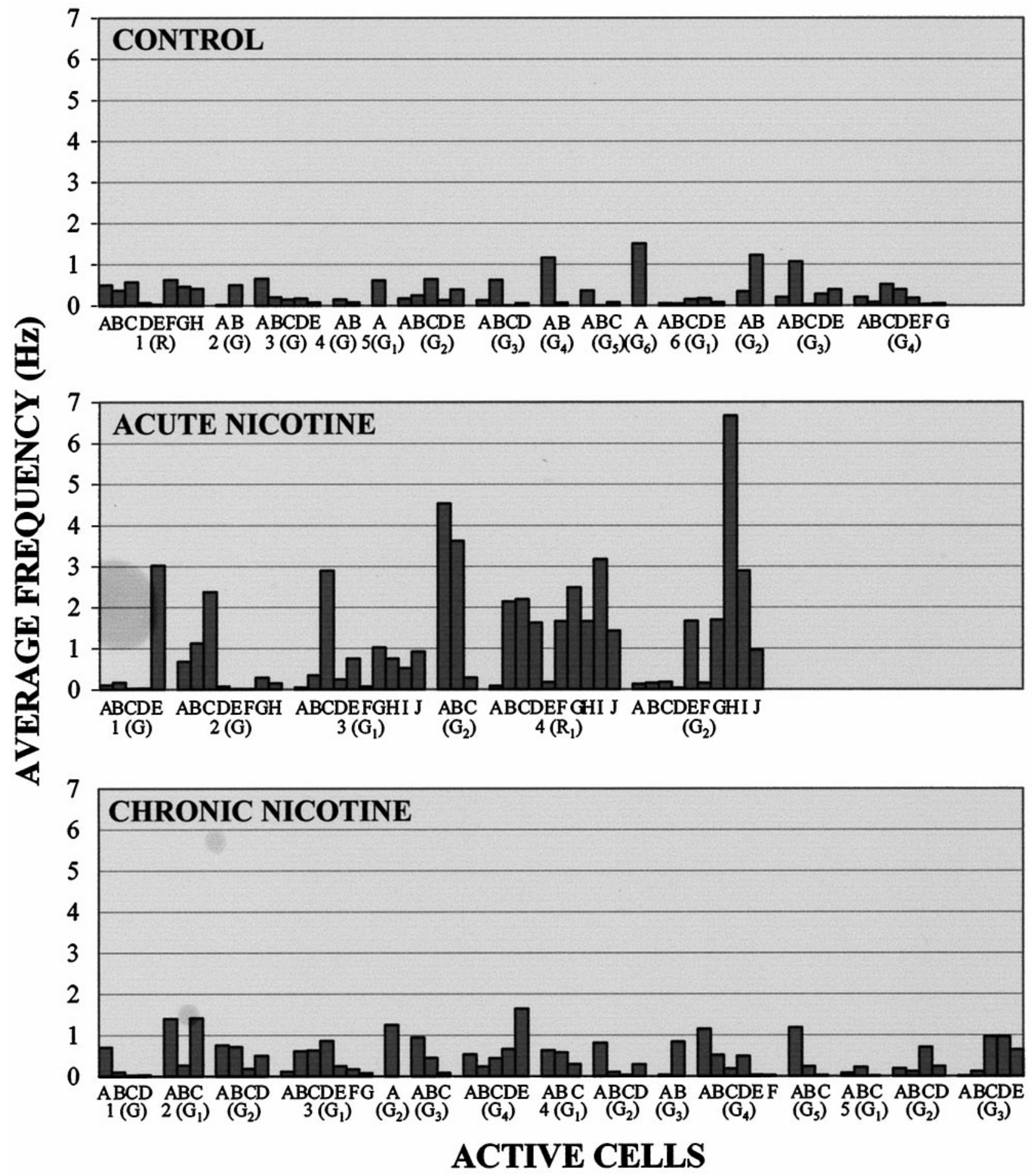

Figure 5. Bar graphs of the average firing frequencies of individual neurons in single ganglia $(G)$ and rings of interconnected ganglia $(R)$. Along the abscissa, the prefixed integers represent different preparations, numerical subscripts represent sequential individual recordings from a given preparation, and the capital letters represent individual neurons. Top, Control. Middle, Acute application of nicotine (a $20 \mu \mathrm{l}$ bolus of $100 \mu \mathrm{M}$ solution added to bath for $\sim 30$ min followed by 30-60 min washout). In preparation $4\left(R_{I}\right)$ (Fig. 7), this wash was performed in steps of 1:10 to 1:20 dilutions from $2 \mu \mathrm{M}$ average concentration in the chamber, to a final concentration of $10 \mathrm{nM}$, over a period of $\sim 60 \mathrm{~min}$. In preparation $4\left(G_{2}\right)$ (Fig. 9), these progressive dilutions were followed by a 30 min wash with normal Ringer's solution. Bottom, Chronic exposure (20-24 hr) to $0.2 \mu \mathrm{M}$ nicotine.

the data set is not yet sufficient to permit statistically significant interpretation of the relevant parameters]. This average behavior is also illustrated graphically in Figure 5 (control). Although average frequencies vary widely, frequencies exceeding $1 \mathrm{~Hz}$ are exceptional. The same data are also displayed as a discrete probability distribution in Figure 6 (control). This shows the percentage of the total number of active neurons (ordinate) exhibiting a given range (abscissa) of average spike frequencies. 

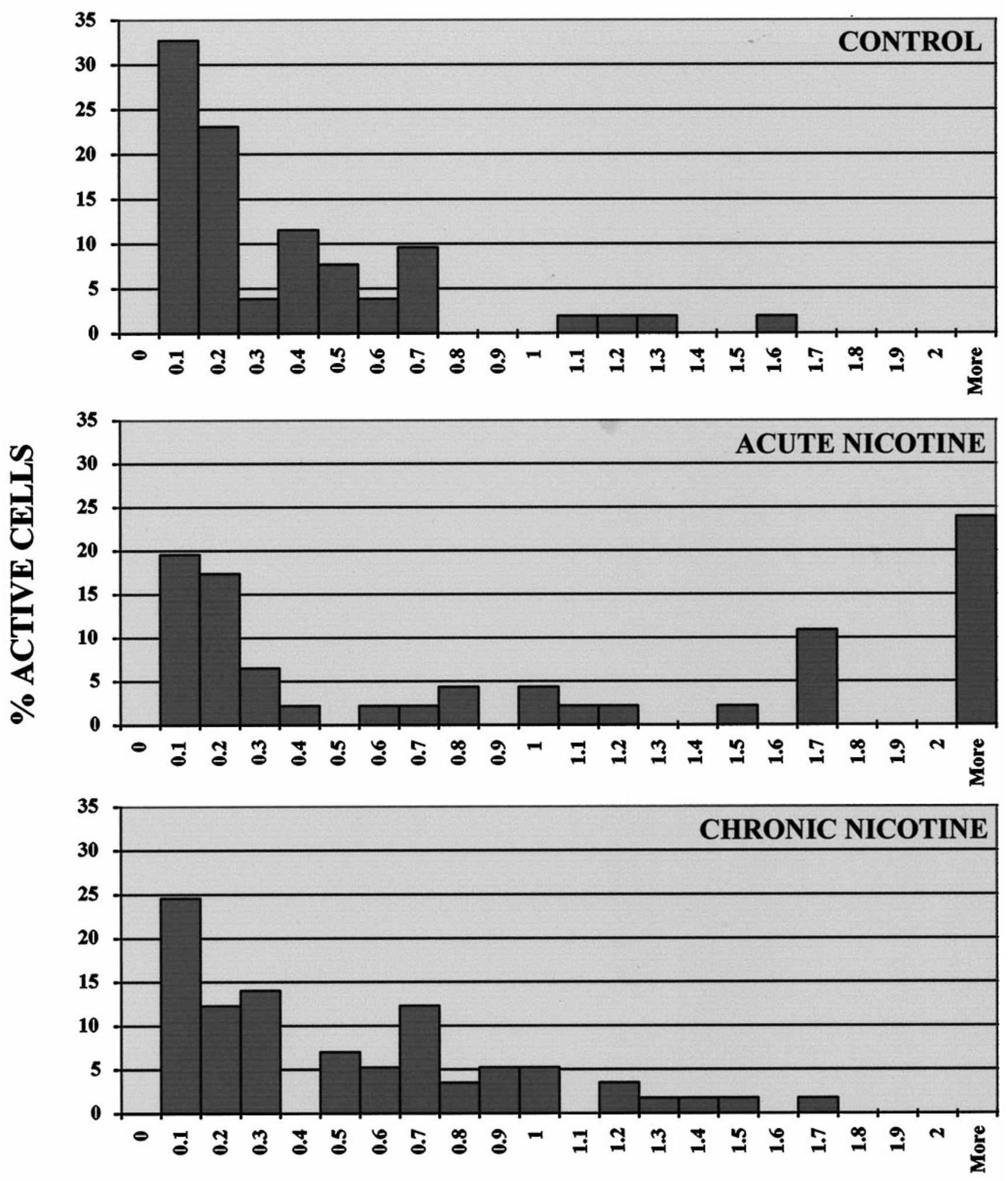

AVERAGE FREQUENCY (Hz)

Figure 6. Discrete probability distributions showing the percentage of active neurons exhibiting average firing frequencies (ordinate) within $0.1 \mathrm{~Hz}$ ranges (abscissa). Top, Control. Middle, Acute application of nicotine. Bottom, Chronic exposure (20-24 hr) to $0.2 \mu \mathrm{M}$ nicotine. 
Table 3. Effect of nicotine on activation, desensitization, and permanent inactivation of human nAChRs

\begin{tabular}{|c|c|c|c|c|c|}
\hline \multirow{2}{*}{$\begin{array}{l}\text { Human } \\
\text { nAChR } \\
\text { subtype }\end{array}$} & \multirow{2}{*}{$\begin{array}{l}\mathrm{EC}_{50} \text { for acti- } \\
\text { vation }\end{array}$} & \multirow{2}{*}{$\begin{array}{l}\mathrm{EC}_{50} \text { for } \\
\text { desensitization }(\mathrm{M})\end{array}$} & \multirow{2}{*}{$\begin{array}{l}\mathrm{EC}_{50} \text { for permanent } \\
\text { inactivation }(\mathrm{M})\end{array}$} & \multicolumn{2}{|c|}{$\begin{array}{l}\text { Fraction of activity expected to remain } \\
\text { after chronic application of } 0.2 \mu \mathrm{M} \\
\text { nicotine followed by washout }(\%)\end{array}$} \\
\hline & & & & $30 \mathrm{~min}$ & $24 \mathrm{hr}$ \\
\hline$\alpha 4 \beta 2$ & $3 \times 10^{-7}$ & $1.7 \times 10^{-8}$ & $4.8 \times 10^{-8}$ & 40 & 10 \\
\hline$\alpha 3 \beta 2 \beta 4 \alpha 5$ & $3 \times 10^{-6}$ & $8.7 \times 10^{-7}$ & $8 \times 10^{-6}$ & $90-100$ & $70-100$ \\
\hline$\alpha 7$ & $4 \times 10^{-5}$ & $3 \times 10^{-8}$ & $1 \times 10^{-8}$ & $15-30$ & 20 \\
\hline
\end{tabular}

From Olale et al. (1997) and Olale, Kuryatov, and Lindstrom, unpublished observations.

\section{Effects of nicotine on the spontaneous patterns of activity of the submucosal network}

Perturbation of a complex system is a useful approach to understanding its behavior. This is particularly true for the study of neuronal networks. Because a vast physiological and pharmacological literature implicates $\mathrm{ACh}$ as an essential neurotransmitter in gastrointestinal function (Kosterlitz and Lees, 1964; Cooke, 1984; Furness and Costa, 1987; Johnson et al., 1996; Kadowaki et al., 1996), and several nAChR subtypes are abundant in the submucous plexus [see immunohistological studies to follow and Kirchgessner and Liu (1998)], nicotine itself seems an obvious choice for perturbing the functional connectivity of the submucous network. It has been shown (Lindstrom et al., 1996; Lindstrom, 1997; Olale et al., 1997) that nAChR subtypes desensitize to different degrees, and with different kinetics, depending on agonist concentration and exposure time. This is reflected in substantially different $\mathrm{EC}_{50}$ values for activation by nicotine, for reversible desensitization, and for irreversible desensitization (Table 3). Because of this, we expected to observe different patterns of activity with acute and chronic exposure to nicotine. Here, the effect of nicotine is examined under two different conditions: (1) acute application of a high concentration of nicotine (e.g., a $20 \mu \mathrm{l}$ bolus of $100 \mu \mathrm{M}$ nicotine added to a $1 \mathrm{ml}$ chamber filled with Ringer's solution), followed by washout within 30-60 min), or (2) chronic exposure (20-24 hr) to a low-nicotine concentration $(0.2 \mu \mathrm{M})$ followed by washout. This low concentration of nicotine simulates the level of the drug found in the blood of heavy smokers.

\section{Acute applications of nicotine and the concomitant washout induce dramatic changes in network connectivity}

When the dissection of the plexus is performed carefully, and the submucous network connectivity is well preserved, the optical recordings erupt with waves of spontaneous activity rushing across the plexus. This spontaneous activity (Figs. 3, 4) varies from sporadic spikes in some neurons, to bursts that last tens of seconds in others, rarely exhibiting an average firing frequency higher than $1 \mathrm{~Hz}$. The character of this spontaneous activity, however, can be drastically affected by a brief exposure to a high concentration of nicotine.

Optical recordings, after washout of the agonist, were obtained not earlier than 30-60 min after application of the agonist. This apparently awkward experimental protocol was designed to circumvent technical limitations. It was not possible to record pharmacological effects during the application itself, because mechanical disturbance after the bolus usually obscured the early activation of the nAChRs. In addition, rapid desensitization of the nAChRs during the period of the mechanical disturbance resulted in complete cessation of detectable activity that could only be reversed by extensive washout.

Figure 7 provides an example of the response of a ring of interconnected ganglia to a brief exposure to nicotine (a $20 \mu \mathrm{l}$ bolus of $100 \mu \mathrm{M}$ agonist added to a $1 \mathrm{ml}$ chamber) recorded optically. Figure $7 A$ shows the image of the ring of ganglia, after staining with di-8-ANEPPS, with the image of the photodiode array superimposed. This composite image was recorded using the $40 \times$ objective (Olympus, $1.4 \mathrm{NA}$ ). Figure $7 B$ illustrates the visual identification of individual neurons within the ring, whose firing patterns are depicted in Figure $7 C$. This panel shows the raster plot that summarizes the firing patterns of the ten active neurons identified by spike sorting in this relatively brief $(40 \mathrm{sec})$ recording.

Figure 8 illustrates a particularly robust burst of activity that developed in a submucous neuron when the nicotine, added acutely 45-60 min earlier (a $20 \mu \mathrm{l}$ bolus of $100 \mu \mathrm{M}$ agonist added to a $1 \mathrm{ml}$ chamber), was washed from the chamber. Firing frequency data from this ganglion and five additional ganglia from a total of four preparations are summarized in Table 2 (acute nicotine) and displayed graphically in Figures 5 and 6. Notice in Figure 5 (acute nicotine) the dramatically increased incidence of firing rates in excess of $2 \mathrm{~Hz}$ [the difference seen here between control and acute nicotine is statistically significant by the MannWhitney $U$ test with an asymptotic significance (two-tailed) of $p=$ 0.002]. This is also reflected in Figure 6 (acute nicotine), the frequency distribution graph, in which $\sim 25 \%$ of all the active cells fire in the high-frequency range.

Figure $8 A$ shows the image of a single ganglion, after staining with di-8-ANEPPS, with the image of the photodiode array superimposed. Figure $8 B$ illustrates the visual identification of individual neurons within the ganglion, whose spike activity is displayed in the raster plot in Figure $8 C$. Notice the burst of activity lasting $>2$ min that was induced in neuron $E$ of this submucous ganglion. Most probably, this remarkably high tonic firing rate $(4-5 \mathrm{~Hz}$ for 2 full minutes; $3.02 \mathrm{~Hz}$ average frequency over the whole length of the record) reflects the recovery from desensitization of nAChRs that followed the bolus of nicotine (see Discussion).

Figure 9 illustrates another example of activity after a brief exposure to a high concentration of nicotine. In this ganglion, 10 cells are active, with four cells (neurons $E, G, H$, and $I$ ) exhibiting higher than average firing rates. In particular, neuron $\mathrm{H}$ sustained a $10 \mathrm{~Hz}$ burst for $>20 \mathrm{sec}$. Several neurons (e.g., neurons $C$ and $G)$ that were active during this recording exhibited, in addition to the action potentials, some optical signals that were clearly distinguishable from the spikes by their longer duration and characteristic humped shape. Samples of these, labeled with asterisks, are illustrated in the $200 \mathrm{msec}$ segments recorded by 10 different 

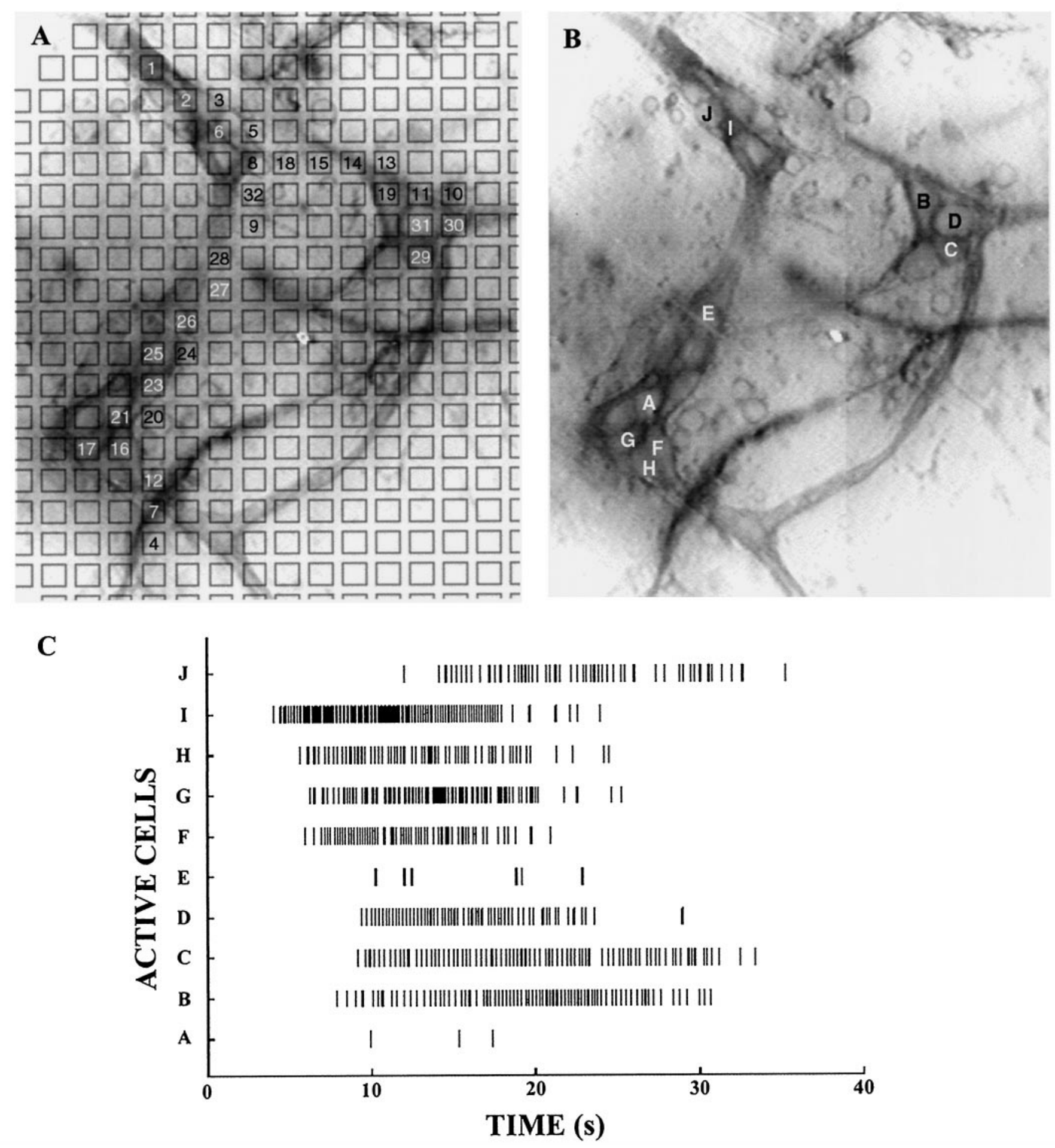

Figure 7. Optical recording of the response of a ring of interconnected submucous ganglia to a brief exposure to nicotine. $A$, The image of the ring of ganglia, after staining with di-8-ANEPPS, with the image of the central region of the photodiode array superimposed. The numbers identify the individual detector elements whose signals were recorded at $2 \mathrm{kHz}$. A $40 \times$ objective (DApo $40 \mathrm{UV}, 1.3$ NA, Olympus) results in each detector monitoring a square region of the ganglion $18 \mu \mathrm{m}$ on a side. The gray scale has been inverted so that increasing fluorescence intensity is represented by darker shades of gray. $B$, Visual identification of the individual neurons whose spike activity is depicted in $C$. $C$, Raster plot depicting the spike activity of the 10 neurons that were active during the $40 \mathrm{sec}$ recording period. In this experiment, phototoxicity was minimized by using astaxanthin (González and Tsien, 1997) in the incubation medium and glucose oxidase and catalase in the staining solution (see Table 2, acute nicotine, preparation 4, 1R). In this particular experiment, the wash was performed in steps of 1:10 to 1:20 dilutions from $2 \mu \mathrm{M}$ average concentration in the chamber, to a final concentration of $10 \mathrm{nM}$, over a period of $\sim 60 \mathrm{~min}$. The associated animation can be accessed at the authors' website (http://loco1.med.upenn.edu/ animation). 

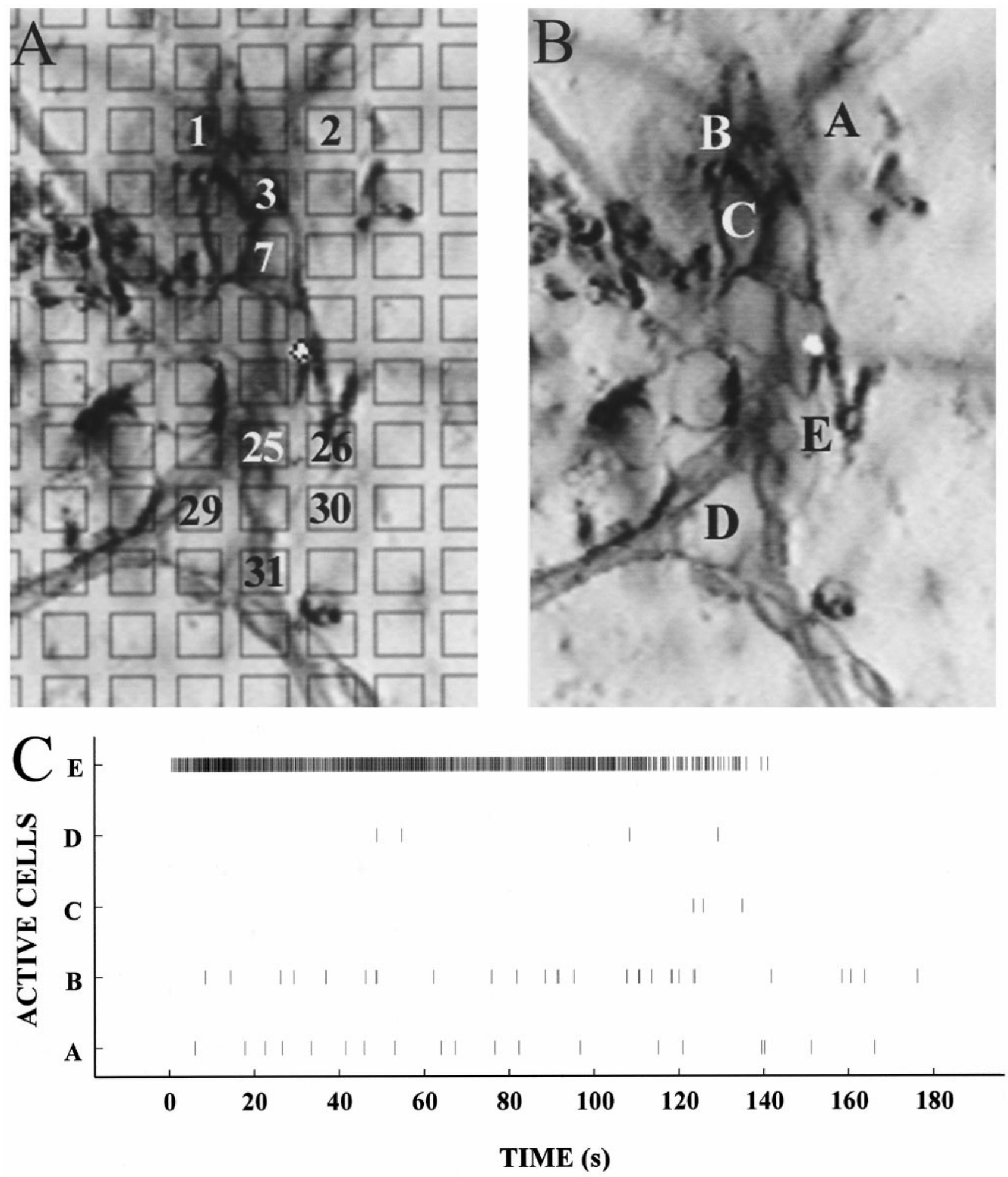

Figure 8. Optical recording of a burst of activity in a single ganglion in response to the washout of an acute application of nicotine. $A$, The image of the ganglion, after staining with di-8-ANEPPS, with the image of the central region of the photodiode array superimposed. The numbers identify the individual detector elements whose signals were recorded at $2 \mathrm{kHz}$. A $40 \times$ objective (DApo $40 \mathrm{UV}, 1.3$ NA, Olympus) results in each detector monitoring a square region of the ganglion $18 \mu \mathrm{m}$ on a side. The gray scale has been inverted so that increasing fluorescence intensity is represented by darker shades of gray. $B$, Visual identification of the five individual neurons whose spike activity is depicted in $C$. $C$, Raster plot depicting the spike activity of the five neurons that were active during the $3 \mathrm{~min}$ recording period. Note, in neuron $E$, the initial 2 min burst having an average spike frequency of 4-5 Hz (see Table 2, acute nicotine, preparation 1, 1G). The record was obtained 45-60 min after washout of the bolus of nicotine from the chamber. The associated animation can be accessed at the authors' website (http://loco1.med.upenn.edu/ animation). 


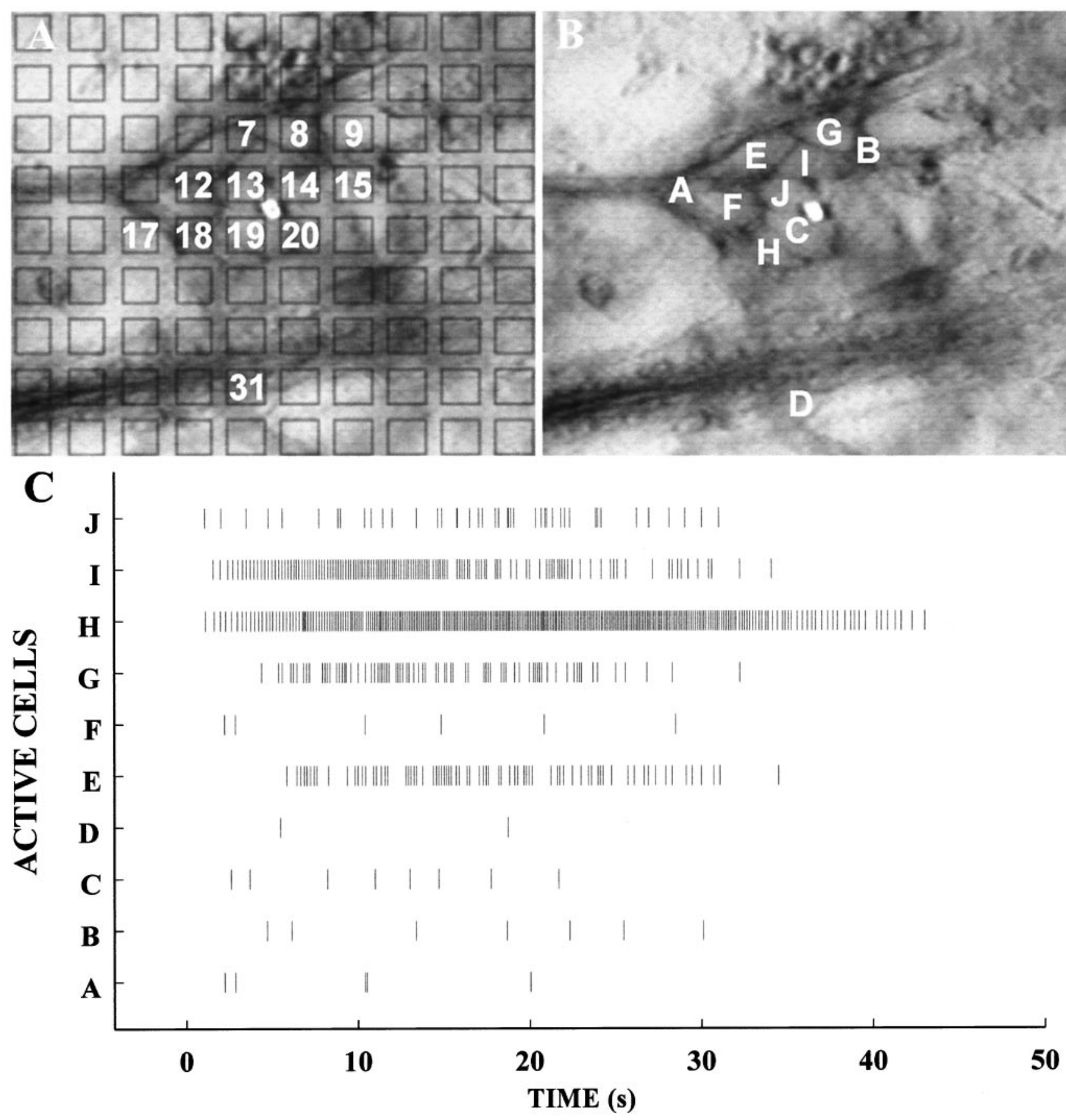

Figure 9. Another optical recording of the increased electrical activity that follows the washout of acutely applied nicotine. $A$, The image of the ganglion, after staining with di-8-ANEPPS, with the image of the central region of the photodiode array superimposed. The numbers identify the individual detector elements whose signals were recorded at $2 \mathrm{kHz}, 40 \times$ objective (DApo $40 \mathrm{UV}, 1.3 \mathrm{NA}$, Olympus), inverted gray scale. $B$, Visual identification of the 10 individual neurons whose spike activity is depicted in $C$. $C$, Raster plot showing the spike activity of the 10 neurons that were active during the $50 \mathrm{sec}$ recording period (see Table 2, acute nicotine, preparation $4,2 \mathrm{G}$ ). The record was obtained $\sim 30$ min after washout of nicotine from the chamber. Because this record was obtained from the same preparation as the record shown in Figure 7, the washout followed progressive dilutions from $2 \mu \mathrm{M}$ average concentration in the chamber, to a final concentration of $1 \mathrm{nM}$, over a period of $60-90$ min. The associated animation can be accessed at the authors' website (http://loco1.med.upenn.edu/ animation).

detectors in Figure 10. These events, having a duration between 10 and $20 \mathrm{msec}$, seem to represent fast EPSPs, most probably cholinergic in origin. It should be noted that, because the MSORTV system used for this experiment has an AC coupling time constant of $110 \mathrm{msec}$, fast synaptic potentials are the only synaptic potentials that can be detected by this optical recording system. If the signals in Figure 10 are, indeed, fast EPSPs, they would represent the first optical recordings of synaptic potentials from mammalian neurons, with single-cell resolution; however, their further characterization must await additional experiments. The optical signals that appear to represent synaptic potentials are comparable in size to those that represent action potentials. 


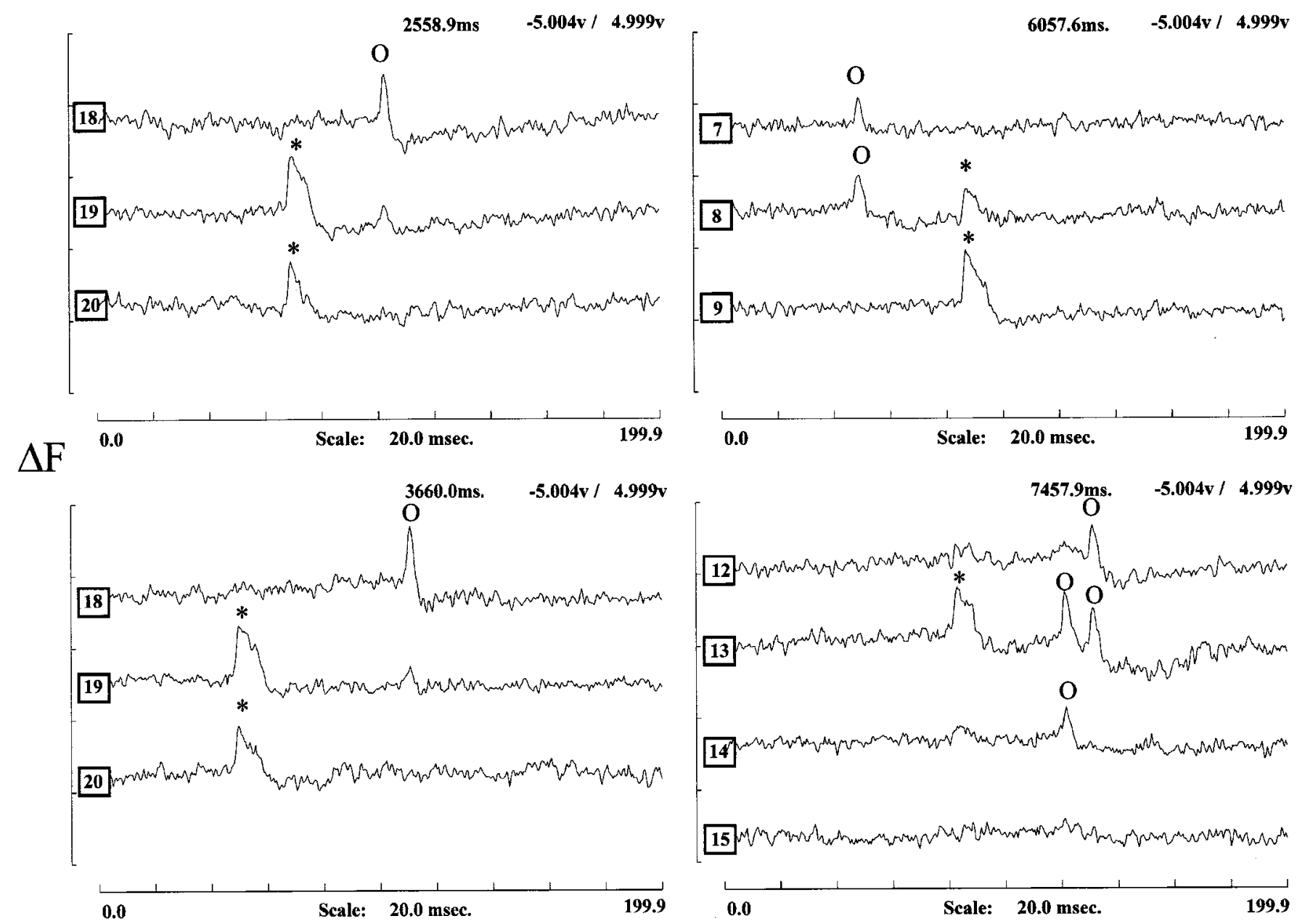

Figure 10. Putative EPSPs recorded optically from a submucous plexus ganglion after the washout of acutely applied nicotine. Segments (200 msec) from the raw data corresponding to the experiment in Figure 9, showing two different types of optical signals. Interspersed with the action potentials (marked by $O \mathrm{~s}$ ), are longer lasting signals, marked by asterisks, that last 10-20 msec, have a humped shape, and may represent EPSPs. Note that no significance can be attached to the relative amplitudes of signals recorded from different membranes (see Results and Table 2, acute nicotine, preparation $4,2 \mathrm{G})$. The AC coupling time constant was $110 \mathrm{msec}$.

This is deceptive. Potentiometric optical signals are proportional not only to membrane voltage, but also to membrane area as well as amount of dye bound. Thus, no significance can be attached to relative amplitudes of signals recorded from different membranes (Salzberg et al., 1977).

\section{Chronic exposure to a low concentration of nicotine followed by washout has little effect on the spontaneous rate of firing of submucous neurons}

In contrast to acute application of nicotine, chronic exposure to a low concentration $(0.2 \mu \mathrm{M})$ of this agonist produces little or no change in the behavior of the submucosal network. Figure 11 illustrates the pattern of activity of a ganglion from a submucous plexus segment that had been incubated in a medium containing $0.2 \mu \mathrm{M}$ nicotine. Here, two neurons, $A$ and $B$, exhibit prolonged tonic bursts, sustaining an average firing rate of $\sim 1 \mathrm{~Hz}$ for $130 \mathrm{sec}$ during a record that was $200 \mathrm{sec}$ long. This activity was recorded $\sim 1$ hr after the preparation had been transferred to a nicotinefree Ringer's solution. Table 2 (chronic nicotine) summarizes data from this (preparation 4, 1G) and 14 additional recordings, from a total of five preparations, and all of these data are displayed graphically in Figures 5 and 6 (chronic nicotine). The difference seen here between control and chronic nicotine is only marginal by the Mann-Whitney $U$ test, with an asymptotic significance (two-tailed) of $p=0.059$. Thus, either the concentration was too low to affect the nAChR subtype involved (e.g., $\alpha 3 \beta 2$ $\mathrm{nAChRs)}$, or despite substantial inactivation there was no effect. Because there was a significant effect (Figs. 5, 6, acute nicotine) after washout of a high concentration of nicotine at a time $(\sim 30$ min) when we would expect most $\alpha 3$ but not $\alpha 4$ or $\alpha 7$ to have recovered from desensitization, that "acute" response might reflect loss of the inhibition that was modulated by presynaptic $\alpha 4$ or $\alpha 7 \mathrm{nAChRs}$ and mediated by $\alpha 3 \mathrm{nAChRs}$ or others. Because the early effect of acute exposure to nicotine was the cessation of activity, rather than the increase that would be expected if most of the activity reflected postsynaptic $\alpha 3 \mathrm{nAChRs}$, these results are puzzling. Clearly, a prerequisite for any elucidation of the complex nicotine results must be the characterization and localization of all of the nAChR subtypes present in the submucous plexus.

\section{Immunocytochemical identification of $\mathrm{nAChR}$ subunits}

MSORTV provides real-time monitoring of the electrical activity of all active neurons but provides no information about either the channels or receptors responsible for shaping that activity. To understand the effects of nicotine on network behavior, therefore, 

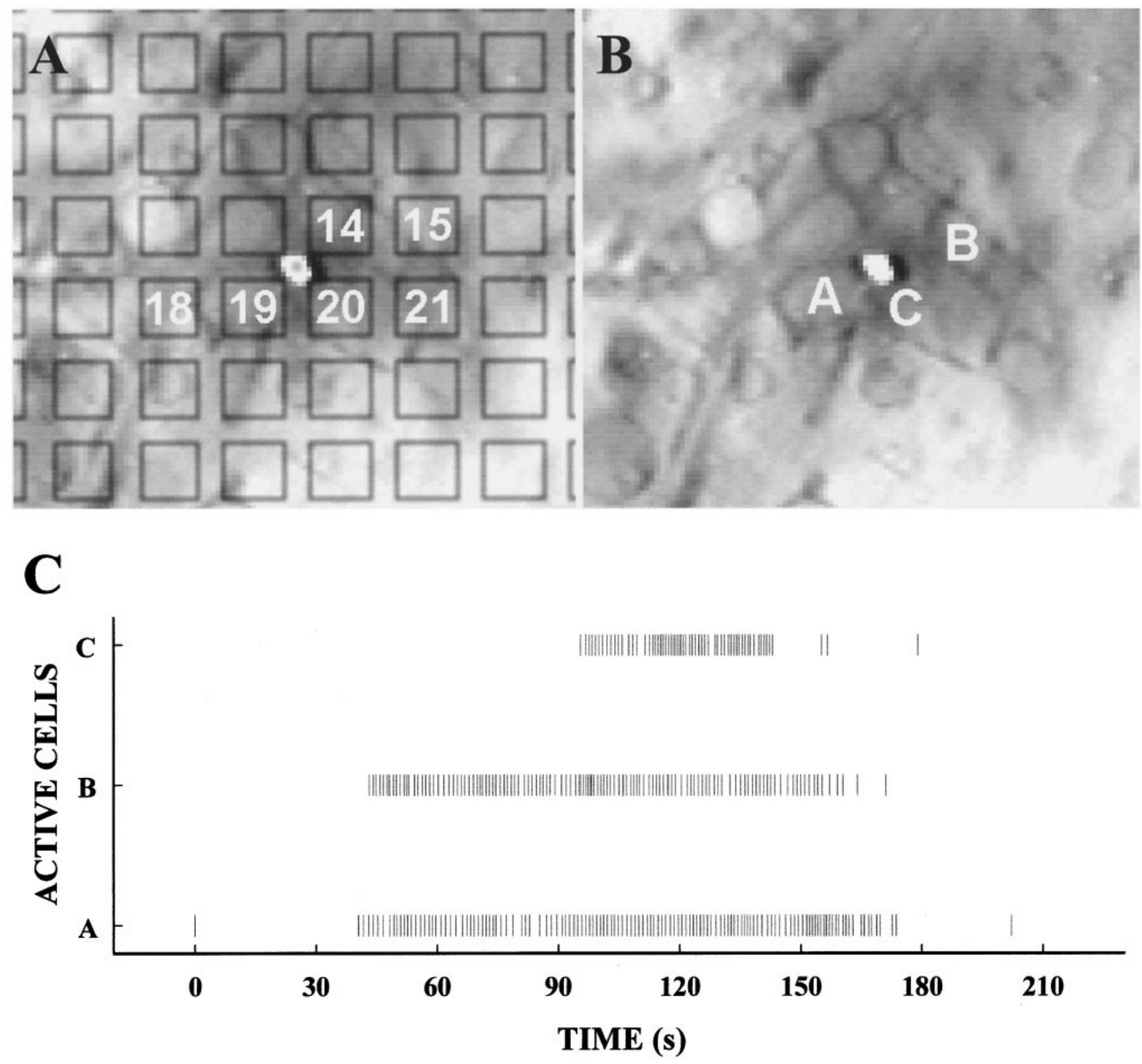

Figure 11. A typical pattern of electrical activity from a submucous plexus segment that had been exposed chronically to $0.2 \mu \mathrm{M}$ nicotine. $A$, The image of the ganglion, after staining with di-8-ANEPPS, with the image of the central region of the photodiode array superimposed. The numbers identify the individual detector elements whose signals were recorded at $2 \mathrm{kHz}$. A $40 \times$ objective (DApo $40 \mathrm{UV}, 1.3 \mathrm{NA}$, Olympus) results in each detector monitoring a square region of the ganglion $18 \mu \mathrm{m}$ on a side; inverted gray scale. $B$, Visual identification of the three individual neurons whose spike activity is depicted in C.C, Raster plot depicting the spike activity of the three neurons that were active during the 3.5 min recording period (see Table 2, chronic nicotine, preparation $1,1 \mathrm{G}$ ). The associated animation can be accessed at the authors' website (http://loco1.med.upenn.edu/ animation).

it is essential to determine which nAChR subtypes are present and to elucidate their role. Kirchgessner and Liu (1998) have used mAb35 (Tzartos et al., 1981), which recognizes neuronal $\alpha$-bungarotoxin ( $\alpha \mathrm{Bgt}$ )-insensitive $\alpha 3$ and $\alpha 5 \mathrm{nAChR}$ subunits, to locate $\mathrm{nAChR}$ protein in guinea pig gut and pancreas. Their results indicated that immunoreactivity to mAb35 was abundant in the submucous plexus and that its distribution in terminals and axons, as well as in cell somata and dendrites, suggested that a subset of nAChRs is presynaptic. They also used a polyclonal antibody raised against the $\alpha$ Bgt-sensitive nAChR subunit $\alpha 7$ and found that a large subset of neurons in submucosal ganglia were $\alpha 7$-immunoreactive and that $\alpha 7$-immunoreactive nerve fibers travel along blood vessels in the submucosa.
Figure 12 shows the localization of mAb35 $(A)$, mAb210 $(B)$, mAb295 $(C)$, and mAb306 $(D)$. These data confirm Kirchgessner and Liu's (1998) findings with mAb35 and corroborate these results by showing that the distribution of $\mathrm{nAChRs}$ that bind $\mathrm{mAb} 35(A)$ is identical to the distribution of nAChRs that bind mAb210 (B) (Tzartos et al., 1987). mAb210 and mAb35 both recognize the main immunogenic region on $\alpha 1 \mathrm{nAChRs}$ of muscle and cross-react with neuronal nAChR $\alpha 3$ and $\alpha 5$ subunits. Furthermore, our results confirm the presence of $\alpha 7$ by showing immunoreactivity with mAb306 (D) (Schoepfer et al., 1990), a monoclonal antibody that recognizes an intracellular $\alpha 7$ epitope, and also demonstrate the presence of $\beta 2$ subunits by immunoreactivity to mAb295 (C) (Whiting and Lindstrom, 1988). Other 

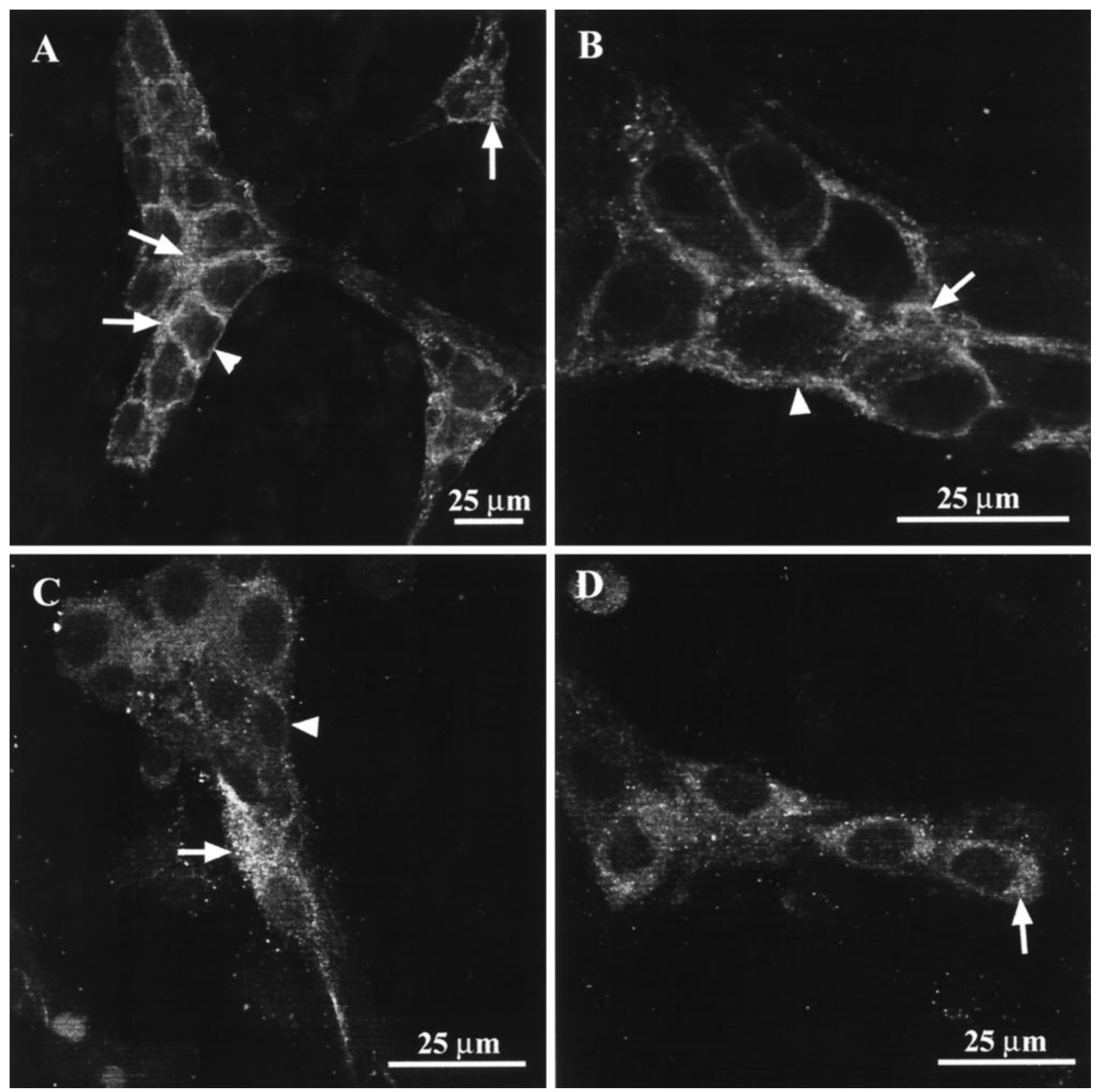

Figure 12. Immunoreactivity to specific nAChR subunits in whole mounts of submucosa. $A$, Confocal micrograph showing the localization of mAb35 immunoreactivity. Section thickness, $1.7 \mu \mathrm{m}$; zoom, 1.25; Leica $40 \times, 1.0$ NA. Arrowhead points to plasma membrane. Arrows point to clusters of receptors; nonpermeabilized tissue. $B$, Confocal micrograph showing localization of mAb210 immunoreactivity. Section thickness, $1.8 \mu$ m; zoom, 1.25 ; $100 \times, 1.4$ NA. Arrowhead points to plasma membrane. Arrow points to cluster of receptors; nonpermeabilized tissue. $C$, Confocal micrograph showing the localization of mAb295 immunoreactivity. Section thickness, $1.4 \mu \mathrm{m}$; zoom, 1.0;; 100×, 1.4 NA. Arrowhead points to plasma membrane. Arrow points to cluster of receptors; nonpermeabilized tissue. $D$, Confocal micrograph showing the localization of mAb306 immunoreactivity. Section thickness, 0.5 $\mu \mathrm{m}$; zoom, 1.0; $100 \times, 1.4$ NA. Arrow points to intracellular staining. Tissue permeabilized with 0.5\% Triton X-100.

nAChR subunits, such as $\beta 4$, may well be present. Ganglionic neurons typically express a mixture of $\alpha 3 \mathrm{nAChRs}$ composed of $\alpha 3$ in combination with $\beta 2$ and/or $\beta 4$, and sometimes also $\alpha 5$ (Conroy and Berg, 1995; Wang et al., 1998). $\alpha 7$ is also often expressed by these neurons (Conroy and Berg, 1995).

Immunoreactivity for $\mathrm{mAb} 35$ and $\mathrm{mAb} 210$ in the absence of permeabilization (Fig. 12A,B) is primarily associated with the plasma membrane (arrowhead) and reveals clustering of nAChRs (arrows). Immunoreactivity for mAb295 in nonpermeabilized tis- sue (Fig. 12C) is also present in the plasma membrane (arrowhead), but its distribution is uneven, with big clusters appearing in a few of the cells (arrow). Permeabilization with Triton X-100 allows cytoplasmic staining with all these monoclonal antibodies (see Fig. $12 D$ for mAb306 (arrow) and Figure 13, $A$ and $B$, for $\mathrm{mAb} 35$ and mAb210), demonstrating cytoplasmic reservoirs of nAChRs and suggesting that they are being actively synthesized. Figure $13 A$ illustrates the relative distribution of immunoreactivity to mAb210 (green), a monoclonal antibody that recognizes 

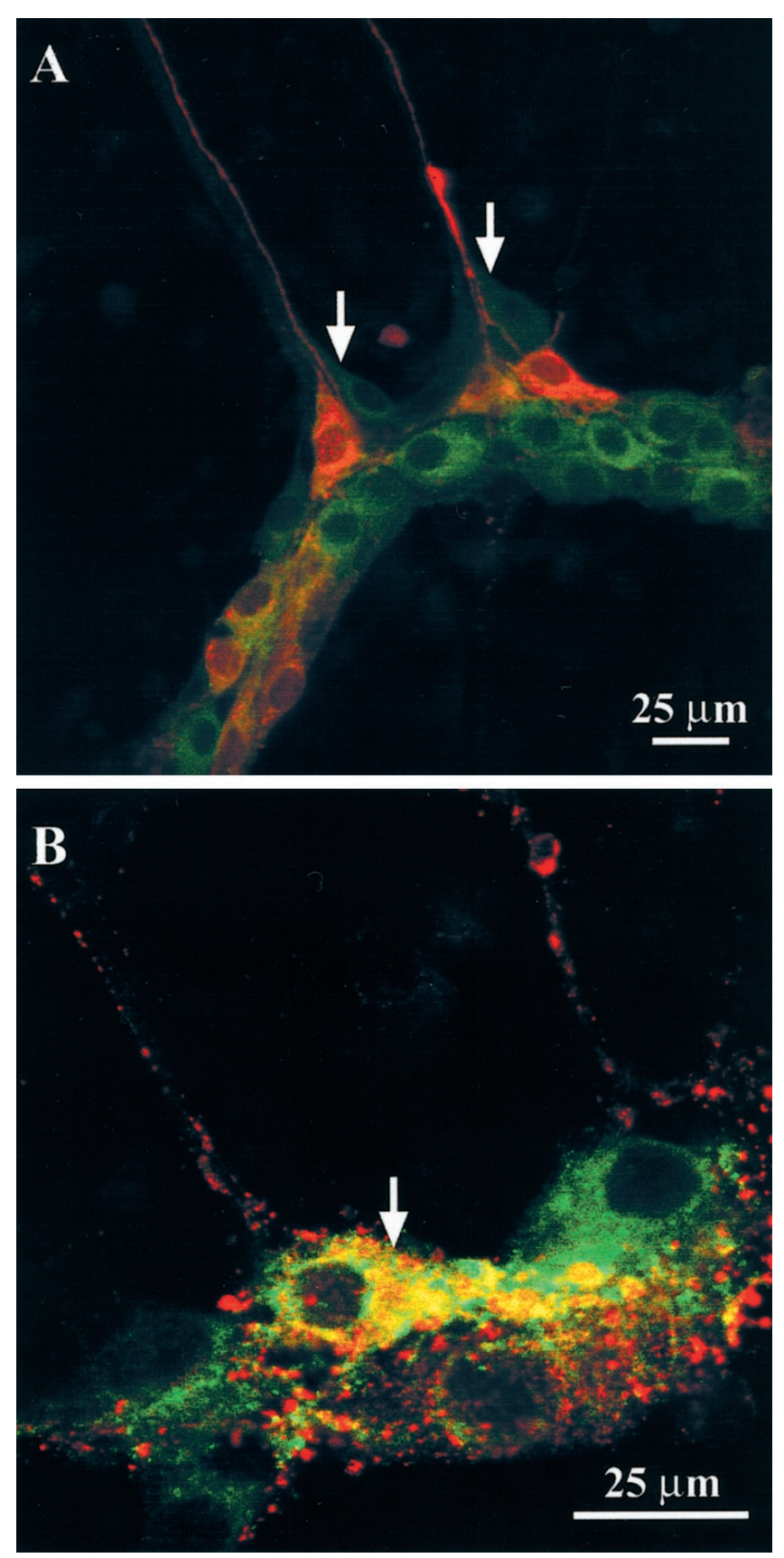

Figure 13. $\alpha 3 / \alpha 5 \mathrm{nAChR}$ subunits can be found in cholinergic and noncholinergic neurons. $A$, Confocal micrograph showing the immunoreactivity to mAb210 receptor $(\alpha 3 / \alpha 5$, green) and NPY (red). Section thickness, $1.1 \mu \mathrm{m}$; zoom, 1.0; $40 \times, 1.25 \mathrm{NA}$. Arrows point to neurons that exhibit very low immunoreactivity to nAChRs and are presumably sensory. $B$, Confocal micrograph showing the immunoreactivity to $\mathrm{mAb} 35$ receptor $(\alpha 3 / \alpha 5$, green $)$ and VIP (red). Section thickness, $1.1 \mu \mathrm{m}$; zoom, 2.27; $40 \times, 1.25$ NA. Tissue permeabilized with $0.5 \%$ Triton X-100.

$\alpha 3 / \alpha 5$ subunits of neuronal nAChRs, and $\alpha \mathrm{NPY}$ (red), an intracellular marker that identifies cholinergic secretomotor neurons in submucosal ganglia (Bornstein and Furness, 1988). The presence of nAChRs in cholinergic neurons increases the probability that some of these nAChRs may be presynaptic. Notice that despite the ubiquity in the distribution of $\alpha 3 / \alpha 5 \mathrm{nAChRs}$, cells positioned near connectives (arrows) tend to exhibit much lower levels of immunoreactivity. Indeed, cells pointing toward connec- tives prove, very often, to be sensory neurons (Kirchgessner and Liu, 1998).

Figure $13 B$ illustrates the relative distribution of immunoreactivity to mAb35 (green), a monoclonal antibody that, together with mAb210, recognizes $\alpha 3 / \alpha 5$ subunits of neuronal nAChRs and $\alpha$ VIP (red), an intracellular marker that identifies noncholinergic secretomotor neurons (Bornstein and Furness, 1988). Here, the overlap of the two markers, apparent in the yellow cell (arrow), demonstrates that $\alpha 3 / \alpha 5 \mathrm{nAChRs}$ can be found in noncholinergic as well as in cholinergic neurons.

\section{DISCUSSION}

The properties of any neuronal ensemble depend not only on the intrinsic conductances of its individual neurons and the specific properties of its many synapses, but on the complex and nonlinear dynamic interactions that result from the multiple parallel connectivity of its component cells. Thus, simple nervous systems, consisting of a limited number of elements (Selverston and Moulins, 1985; Marder, 1998), offer the best hope for understanding the dynamic electrical and chemical interactions that give rise to patterns of effective connectivity and generate behavior in mammals. Because isolated segments of the submucous plexus contain a restricted number of neurons, collected into small ganglia and located within a single optical plane, these networks are uniquely amenable to analysis by optical means. Indeed, multiple site optical recording techniques, combined with the appropriate analytical tools, make the mammalian submucous plexus a preparation extremely conducive to understanding the dynamics of neuronal assemblies. The use of optical methods to study the role of nicotine and its receptors in the behavior of the submucosal network was motivated by the significance of cholinergic transmission in the ENS.

\section{Advantages and limitations of multiple-site optical recording for studying spontaneous patterns of activity in the submucosal network}

This report demonstrates the successful use of MSORTV to study the electrical activity from all of the neurons in a ganglion or a ring of submucosal ganglia. Activity could be recorded continuously and simultaneously, preserving single-cell resolution, from up to 40 neurons, for $\sim 5 \mathrm{~min}$, and, under appropriate conditions, optical signals that may represent fast synaptic events were observed (Fig. 10). Pharmacological interventions, on the other hand, although feasible, were more problematic. Time constraints caused by phototoxicity of di-8-ANEPPS did not allow repetitive recordings from the same optical field, precluding bracket experiments using the same ganglia. In addition, fast desensitization of nAChRs, when nicotine was applied acutely through a pressure injector or as a bolus, did not permit a detailed examination of the initial activation of nAChRs after addition of the agonist. Despite these limitations, the experiments yielded interesting results. First, a brief exposure to acute application of nicotine, followed by washout, dramatically increased the firing rates of a subset of submucous neurons, elevating the average frequency of firing from $<1$ up to $7 \mathrm{~Hz}$. Second, long exposure $(\sim 24 \mathrm{hr}$ ) to $0.2 \mu \mathrm{M}$ nicotine, the same concentration found in the blood of heavy smokers, had little or no effect on the frequency of firing measured after washout.

\section{Effects of nicotine at the network level}

Immunocytochemical experiments using mAbs to different subunits of the $\mathrm{nAChR}$ revealed the presence of subunits $\alpha 3 / \alpha 5, \alpha 7$, and $\beta 2$, and their distribution (Kirchgessner and Liu, 1998) 
supports the idea that at least some of these nAChRs are presynaptic. Indeed, McGehee et al. (1995), studying nicotine enhancement of fast excitatory synaptic transmission in the CNS, have postulated that a predominant, if not exclusive, role of CNS presynaptic nAChRs may be to modify excitability. This hypothesis is supported by the results of Radcliffe and Dani (1998), who found that a brief stimulation of nAChRs enhances hippocampal glutamatergic synaptic transmission on two different time scales (seconds and minutes), altering the relationship between consecutively evoked synaptic events. They established that this enhancement required extracellular calcium and was produced by the activation of presynaptic $\alpha 7$-containing nAChRs. Although one form of glutamatergic enhancement lasted only for seconds, another form lasted for minutes after the nicotinic stimulation had ceased and the nicotinic agonist had been washed away. The latter enhancement was, thus, observed under conditions that closely resemble our protocol. They postulated that the synaptic enhancement that lasts for minutes results from $\mathrm{nAChR}$ activity, capable of originating calcium-dependent mechanisms known to induce glutamatergic synaptic plasticity. These findings of Radcliffe and Dani (1998), taken together with the demonstration by Liu et al. (1997) of the existence of glutamatergic circuitry in the ENS, may explain our observations on the effects of nicotine on the submucosal network.

Olale et al. (1997) have demonstrated that chronic nicotine exposure affects differentially the function of $\alpha 3, \alpha 4$, and $\alpha 7$ neuronal nAChR subtypes. They showed that chronic exposure to submicromolar concentrations of nicotine irreversibly inactivates many $\alpha 4 \beta 2$ nAChRs and $\alpha 7 \mathrm{nAChRs,} \mathrm{although} \mathrm{largely} \mathrm{sparing} \alpha 3$ nAChRs. These results could explain, in part, the different behavior seen in submucous plexus preparations after exposure to nicotine for brief periods of time versus long exposures to very low concentrations of the agonist.

Relatively little is known about the functional role of nAChRs in enteric neuronal networks. In the chick ciliary ganglion, $\alpha 3$ nAChRs are located postsynaptically and perisynaptically, $\alpha 7$ $\mathrm{nAChRs}$ are located perisynaptically, and $\alpha 4 \mathrm{nAChRs}$ are absent altogether (Horch and Sargent, 1995). Also, both $\alpha 3$ and $\alpha 7$ nAChRs are known to mediate synaptic transmission in the chick ciliary ganglion (Ullian et al., 1997). Human nAChR subtypes have been expressed in Xenopus oocytes (Olale et al., 1997), and their $\mathrm{EC}_{50}$ values for activation and inactivation by nicotine have been determined and are shown in Table 3 (Olale et al., 1997) (F. Olale, A. Kuryatov, and J. Lindstrom, unpublished observations). Assuming that nAChRs in submucosal ganglia are distributed in a similar manner to those in the chick ciliary ganglion and that they behave like cloned human nAChRs expressed in Xenopus oocytes, then the results obtained with the nicotine exposure regimens described here could be predicted. Extrapolation from the human data suggests that the percent activity expected to remain after $24 \mathrm{hr}$ exposure to $0.2 \mu \mathrm{M}$ nicotine should be $10 \%$ for $\alpha 4 \beta 2,20 \%$ for $\alpha 7$, and $70-100 \%$ for $\alpha 3 \beta 2 \beta 4 \alpha 5$. Thus, overnight exposure of submucosal ganglia to $0.2 \mu \mathrm{M}$ nicotine followed by washout would be expected to have little or no effect, whereas exposure to concentrations $2-100 \mu \mathrm{M}$ for $\sim 30 \mathrm{~min}$ followed by washout would be expected to result in a reduction of activity, because of slight inactivation of $\alpha 3$ and nearly complete inactivation of $\alpha 7$. Instead, dramatic activation was observed. This could be explained by the loss of inhibition, modulated by nAChRcontaining circuits. That is, partial inactivation of $\alpha 4$ or $\alpha 7$ nAChRs, involved presynaptically or postsynaptically in releasing inhibitory neurotransmitters, may then permit sustained activa- tion of circuits containing activatable postsynaptic nAChRs and other excitatory receptors. The data presented here do not provide sufficient information to determine unequivocally whether the observed effects of nicotine on the spontaneous patterns of activity of the submucous plexus are presynaptic or postsynaptic in origin, or both. MSORTV cannot replace traditional electrophysiological methods for characterizing the functional molecular details of different nAChR subtypes or for studying specific synaptic interactions. However, these data demonstrate the unique capability of optical methods for revealing the far reaching and unexpectedly disproportionate consequences that a simple pharmacological intervention may generate at the network level. Future experiments, combining multiple site optical recording with electrophysiological studies and further immunocytochemical characterization of nAChRs subunits will be required to describe more fully the role of $\mathrm{nAChRs}$ in the enteric networks, in health and disease.

\section{REFERENCES}

Bedlack Jr RS, Wei M, Loew LM (1992) Localized membrane depolarizations and localized calcium influx during electric field-guided neurite growth. Neuron 9:393-403.

Bornstein JC, Furness JB (1988) Correlated electrophysiological and histochemical studies of submucous neurons and their contribution to understanding enteric neural circuits. J Auton Nerv Syst 25:1-13.

Conroy WG, Berg DK (1995) Neurons can maintain multiple classes of nicotinic acetylcholine receptors distinguished by different subunit compositions. J Biol Chem 270:4424-4431.

Cooke HJ (1984) Influence of enteric cholinergic neurons on mucosal transport in guinea pig ileum. Am J Physiol 246:G263-G267.

Di Mascio P, Devasagayam TP, Kaiser S, Sies H (1990) Carotenoids, tocopherols and thiols as biological singlet molecular oxygen quenchers. Biochem Soc Trans 18:1054-1056.

Furness JB, Costa M (1979) Projections of intestinal neurons showing immunoreactivity for vasoactive intestinal polypeptide are consistent with these neurons being the enteric inhibitory neurons. Neurosci Lett 15:199-204.

Furness JB, Costa M (1987) The enteric nervous system. New York: Churchill Livingstone.

Furness JB, Costa M, Keast JR (1984) Choline acetyltransferase- and peptide immunoreactivity of submucous neurons in the small intestine of the guinea-pig. Cell Tissue Res 237:329-336.

Furness JB, Bornstein JC, Pompolo S, Young HM, Kunze WAA, Kelly H (1994) The circuitry of the enteric nervous system. Neurogastroenterol Motil 6:241-253.

Gerstein GL, Aertsen AM (1985) Representation of cooperative firing activity among simultaneously recorded neurons. J Neurophysiol 54:1513-1528.

Gerstein GL, Mandelbrot B (1964) Random walk models for the spike activity of a single neuron. Biophys Journal 4:41-68.

Gerstein GL, Perkel DH, Dayhoff JE (1985) Cooperative firing activity in simultaneously recorded populations of neurons: detection and measurement. J Neurosci 5:881-889.

González JE, Tsien RY (1997) Improved indicators of cell membrane potential that use fluorescence resonance energy transfer. Chem Biol 4:269-277.

Green JT, Thomas GA, Rhodes J, Evans BK, Russell MA, Feyerabend C, Fuller GS, Newcombe RG, Sandborn WJ (1997a) Pharmacokinetics of nicotine carbomer enemas: a new treatment modality for ulcerative colitis. Clin Pharmacol Ther 61:340-348.

Green JT, Thomas GA, Rhodes J, Williams GT, Evans BK, Russell MA, Feyerabend C, Rhodes P, Sandborn WJ (1997b) Nicotine enemas for active ulcerative colitis-a pilot study. Aliment Pharmacol Ther 11:859-863.

Grinvald A, Frostig RD, Lieke E, Hildesheim R (1988) Optical imaging of neuronal activity. Physiol Rev 68:1285-1366.

Hirst GD, McKirdy HC (1975) Synaptic potentials recorded from neurones of the submucous plexus of guinea-pig small intestine. J Physiol (Lond) 249:369-385.

Horch HL, Sargent PB (1995) Perisynaptic surface distribution of mul- 
tiple classes of nicotinic acetylcholine receptors on neurons in the chicken ciliary ganglion. J Neurosci 15:7778-7795.

Johnson PJ, Bornstein JC, Yuan SY, Furness JB (1996) Analysis of contributions of acetylcholine and tachykinins to neuro-neuronal transmission in motility reflexes in the guinea-pig ileum. $\mathrm{Br} \mathrm{J}$ Pharmacol 118:973-983.

Kadowaki M, Wade PR, Gershon MD (1996) Participation of 5-HT3, 5-HT4, and nicotinic receptors in the peristaltic reflex of guinea pig distal colon. Am J Physiol 271:G849-G857.

Kalyanaraman B, Feix JB, Sieber F, Thomas JP, Girotti AW (1987) Photodynamic action of merocyanine 540 on artificial and natural cell membranes: involvement of singlet molecular oxygen. Proc Natl Acad Sci USA 84:2999-3003.

Kirchgessner AL, Liu MT (1998) Immunohistochemical localization of nicotinic acetylcholine receptors in the guinea pig bowel and pancreas. J Comp Neurol 390:497-514.

Kosterlitz HW, Lees GM (1964) Pharmacological analysis of intrinsic intestinal reflexes. Pharmacol Rev 16:301-339.

Lindstrom J (1996) Neuronal nicotinic acetylcholine receptors. In: Ion channels, Vol 4 (Narahashi T, ed), pp 377-450. New York: Plenum.

Lindstrom J (1997) Nicotinic acetylcholine receptors in health and disease. Mol Neurobiol 15:193-222.

Lindstrom J, Anand R, Gerzanich V, Peng X, Wang F, Wells G (1996) Structure and function of neuronal nicotinic acetylcholine receptors. Prog Brain Res 109:125-137.

Liu MT, Rothstein JD, Gershon MD, Kirchgessner AL (1997) Glutamatergic enteric neurons. J Neurosci 17:4764-4784.

Maldonado PE, Gerstein GL (1996) Neuronal assembly dynamics in the rat auditory cortex during reorganization induced by intracortical microstimulation. Exp Brain Res 112:431-441.

Marder E (1998) From biophysics to models of network function. Annu Rev Neurosci 21:25-45.

McGehee DS, Heath MJ, Gelber S, Devay P, Role LW (1995) Nicotine enhancement of fast excitatory synaptic transmission in CNS by presynaptic receptors [see comments]. Science 269:1692-1696.

Obaid AL, Salzberg BM (1997) Optical studies of an enteric plexus: recording the spatio-temporal patterns of activity of an intact network during electrical stimulation and pharmacological interventions. Soc Neurosci Abstr 23:2097.

Obaid AL, Koyano T, Connor JA, Salzberg BM (1994) Optical studies of a simulated immune response in an enteric nervous system: measurements of electrical activity and $\left[\mathrm{Ca}^{2+}\right]_{\mathrm{i}}$ with single cell resolution. Soc Neurosci Abstr 20:103.

Obaid AL, Farries MA, Kisley MA, Sakai T, Salzberg BM (1996a) Optical studies of an enteric network: simultaneous recording of electrical activity from several interconnected submucous ganglia with single cell resolution. Soc Neurosci Abstr 22:1642.

Obaid AL, Farries MA, Kisley MA, Sakai T, Salzberg BM (1996b) Simultaneous optical recording of electrical activity with single cell resolution from several ganglia in a mammalian plexus. J Gen Physiol 108:27a-28a.

Obaid AL, Zou D-J, Rohr S, Salzberg BM (1992) Optical recording with single cell resolution from a simple mammalian nervous system: electrical activity in ganglia from the submucous plexus of the guinea-pig ileum. Biol Bull 183:344-346.

Olale F, Gerzanich V, Kuryatov A, Wang F, Lindstrom J (1997) Chronic nicotine exposure differentially affects the function of human $\alpha 3, \alpha 4$, and $\alpha 7$ neuronal nicotinic receptor subtypes. J Pharmacol Exp Ther 283:675-683.
Osborne MJ, Stansby G (1994) Smoking and chronic inflammatory bowel disease. J Royal Soc Health 114:317-319.

Oxford GS, Pooler JP, Narahashi T (1977) Internal and external application of photodynamic sensitizers on squid giant axons. J Membr Biol 36:159-173.

Parsons TD, Salzberg BM, Obaid AL, Raccuia-Behling F, Kleinfeld D (1991) Long-term optical recording of patterns of electrical activity in ensembles of cultured Aplysia neurons. J Neurophysiol 66:316-333.

Pooler J (1972) Photodynamic alteration of sodium currents in lobster axons. J Gen Physiol 60:367-387.

Porter AJ, Wattchow DA, Brookes SJ, Schemann M, Costa M (1996) Choline acetyltransferase immunoreactivity in the human small and large intestine. Gastroenterology 111:401-408.

Radcliffe KA, Dani JA (1998) Nicotinic stimulation produces multiple forms of increased glutamatergic synaptic transmission. J Neurosci 18:7075-7083.

Rohr S, Salzberg BM (1994) Multiple site optical recording of transmembrane voltage (MSORTV) in patterned growth heart cell cultures: assessing electrical behavior, with microsecond resolution, on a cellular and subcellular scale. Biophys J 67:1301-1315.

Salzberg BM (1983) Optical recording of electrical activity in neurons using molecular probes. In: Current methods in cellular neurobiology (Barker J, McKelvy J, eds.), pp 139-187. New York: Wiley.

Salzberg BM, Grinvald A, Cohen LB, Davila HV, Ross WN (1977) Optical recording of neuronal activity in an invertebrate central nervous system: simultaneous monitoring of several neurons. J Neurophysiol 40:1281-1291.

Schemann M, Sann H, Schaaf C, Mader M (1993) Identification of cholinergic neurons in enteric nervous system by antibodies against choline acetyltransferase. Am J Physiol 265:G1005-G1009.

Schoepfer R, Conroy WG, Whiting P, Gore M, Lindstrom J (1990) Brain $\alpha$-bungarotoxin binding protein cDNAs and mAbs reveal subtypes of this branch of the ligand-gated ion channel gene superfamily. Neuron 5:35-48.

Selverston AI, Moulins M (1985) Oscillatory neural networks. Annu Rev Physiol 47:29-48.

Tzartos SJ, Rand DE, Einarson BL, Lindstrom JM (1981) Mapping of surface structures of electrophorus acetylcholine receptor using monoclonal antibodies. J Biol Chem 256:8635-8645.

Tzartos S, Hochschwender S, Vasquez P, Lindstrom J (1987) Passive transfer of experimental autoimmune myasthenia gravis by monoclonal antibodies to the main immunogenic region of the acetylcholine receptor. J Neuroimmunol 15:185-194.

Ullian EM, McIntosh JM, Sargent PB (1997) Rapid synaptic transmission in the avian ciliary ganglion is mediated by two distinct classes of nicotinic receptors. J Neurosci 17:7210-7219.

Wang F, Gerzanich V, Wells GB, Anand R, Peng X, Keyser K, Lindstrom $\mathrm{J}$ (1996) Assembly of human neuronal nicotinic receptor $\alpha 5$ subunits with $\alpha 3, \beta 2$, and $\beta 4$ subunits. J Biol Chem 271:17656-17665.

Wang F, Nelson ME, Kuryatov A, Olale F, Cooper J, Keyser K, Lindstrom J (1998) Chronic nicotine treatment up-regulates human $\alpha 3 \beta 2$ but not $\alpha 3 \beta 4$ acetylcholine receptors stably transfected in human embryonic kidney cells. J Biol Chem 273:28721-28732.

Whiting PJ, Lindstrom JM (1988) Characterization of bovine and human neuronal nicotinic acetylcholine receptors using monoclonal antibodies. J Neurosci 8:3395-3404.

Wood JD (1994) Physiology of the enteric nervous system. In: Physiology of the gastrointestinal tract, Ed 3 (Johnson LR, Alpers DH, Jacobson ED, Walsh JH, eds), pp 423-482. New York: Raven. 